\title{
Newly Generated Liquid Waste Processing Alternatives Study Volume 1
}

William H. Landman, Jr. Steven O. Bates Bruce E. Bonnema Stanley L. Palmer Anna K. Podgorney Stephanie Walsh

September 2002

Idaho National Engineering and Environmental Laboratory Bechtel BWXT Idaho, LLC 


\section{DISCLAIMER}

This information was prepared as an account of work sponsored by an agency of the U.S. Government. Neither the U.S. Government nor any agency thereof, nor any of their employees, makes any warranty, express or implied, or assumes any legal liability or responsibility for the accuracy, completeness, or usefulness of any information, apparatus, product, or process disclosed, or represents that its use would not infringe privately owned rights. References herein to any specific commercial product, process, or service by trade name, trademark, manufacturer, or otherwise does not necessarily constitute or imply its endorsement, recommendation, or favoring by the U.S. Government or any agency thereof. Views and opinions of authors expressed herein do not necessarily state or reflect those of the U.S. Government or any agency thereof. 
INEEL/EXT-02-01160

Volume 1

\title{
Newly Generated Liquid Waste Processing Alternatives Study Volume 1
}

\author{
William H. Landman Jr. \\ Steven O. Bates \\ Bruce E. Bonnema \\ Stanley L. Palmer \\ Anna K. Podgorney \\ Stephanie Walsh
}

September 2002

\section{Idaho National Engineering and Environmental Laboratory Design Engineering Department Idaho Falls, Idaho 83415}

\section{Prepared for the}

U.S. Department of Energy

Assistant Secretary for Environmental Management

Under DOE Idaho Operations Office

Contract DE-AC07-99ID13727 



\begin{abstract}
This report identifies and evaluates three options for treating newly generated liquid waste at the Idaho Nuclear Technology and Engineering Center of the Idaho National Engineering and Environmental Laboratory. The three options are: (a) treat the waste using processing facilities designed for treating sodium-bearing waste, (b) treat the waste using subcontractor-supplied mobile systems, or (c) treat the waste using a special facility designed and constructed for that purpose. In studying these options, engineers concluded that the best approach is to store the newly generated liquid waste until a sodium-bearing waste treatment facility is available and then to co-process the stored inventory of the newly generated waste with the sodium-bearing waste. After the sodium-bearing waste facility completes its mission, two paths are available. The newly generated liquid waste could be treated using the subcontractor-supplied system or the sodium-bearing waste facility or a portion of it. The final decision depends on the design of the sodium-bearing waste treatment facility, which will be completed in coming years.
\end{abstract}




\section{SUMMARY}

The Idaho Nuclear Technology and Engineering Center (INTEC) has completed its mission in reprocessing spent nuclear fuel and is managing and disposing of wastes from those reprocessing operations. Part of dealing with this legacy is treating and disposing of liquid wastes remaining in various storage tanks at INTEC. This waste is designated as sodium-bearing waste (SBW). The Idaho National Engineering and Environmental Laboratory (INEEL) also manage newly generated liquid waste (NGLW), which continues to be generated from ongoing operations.

Presently, the SBW is stored in large underground tanks in the Tank Farm Facility (TFF) at INTEC. A 1995 Settlement Agreement between the State of Idaho, Department of Energy (DOE), and U.S. Navy requires that treatment of the SBW be completed by December 31, 2012. The DOE Idaho Operations Office (DOE-ID) has also mandated that transfer of NGLW to the TFF cease by September 2005. The Idaho Tank Farm Project (ITFP) is responsible for treating the current inventory of SBW, safely closing the tanks in which the SBW is stored, and remediating the radioactively contaminated soils adjacent to the storage tanks. The ITFP is also responsible developing a management scheme for NGLW.

This report discusses the evaluation of options for managing NGLW at INTEC. The options considered are:

- $\quad$ Hold for SBW processing, which involves storage of the NGLW in Resource Conservation and Recovery Act (RCRA)-compliant tanks until the facility for treating SBW is available for treating NGLW

- $\quad$ Treat and dispose of the NGLW by employing a subcontractor with a commercial process to treat the NGLW on an intermittent basis

- $\quad$ Design and construct a new facility at INTEC to treat NGLW.

Prior to evaluating these options, some estimate of the quantity and characteristics of the NGLW was needed, as well as a scheme for storing the NGLW until it is processed. Estimating the quantity and characteristics (physical, chemical, and radiological) of the NGLW that will be generated is particularly difficult because there are a number of factors (e.g., facility closure approaches) that can affect both volume and properties. A total of about 2,500,000 gallons of dilute liquid waste will be generated between 2005 and 2020, mainly from decontamination activities, wastes from the CPP-601 laboratory drains, and in-leakage to the various sumps in structures at INTEC. This large volume of dilute waste can cost-effectively be reduced in volume by a factor of about 20 (overall) using the INTEC evaporator systems to about 128,000 gallons. 
Chemically, the NGLW is much more acidic than SBW and has less dissolved solids and more organic contaminants (from decontamination solutions) than the SBW. Radiologically, the NGLW is estimated to be much less contaminated than the SBW and the liquid is not transuranic (TRU) waste (i.e., the NGLW contains less than $100 \mathrm{nCi} / \mathrm{g}$ of alpha emitting isotopes with masses greater than uranium). From a waste classification perspective, some NGLW streams are clearly lowlevel waste (LLW) or mixed LLW (MLLW). Others, however, come from facilities that have been designated high level waste (HLW) facilities and may require a waste incidental to reprocessing (WIR) determination by either citation or evaluation before they can be designated as TRU, MLLW, or LLW.

The proposed NGLW storage scheme employs permitting and using tanks VES-WM-100, VES-WM-101, and VES- WM-102 after 2005 for storing NGLW. These tanks are located in underground vaults near building CPP-604. They provide adequate volume, based on current generation estimates, to accumulate NGLW for the periods of time considered in these options. These tanks are also a good choice because they can be accessed, by combinations of various valve boxes at INTEC, from nearly anywhere at INTEC. However, this access can be affected by facility closures and other INTEC projects, such as the ITFP and this must be kept in mind as these activities proceed. It should also be noted that these tanks were previously used in operations involving HLW and therefore may require a WIR decision before using them for storage of nonHLW.

After assessing the various options and comparing life cycle costs, the proposed NGLW management scheme is a combination of two of them. It is recommended that the NGLW generated between 2005 and the end of the SBW processing campaign be co-processed with SBW and that a subcontractorprovided commercial process be used afterwards (2011 through 2020 or later). Co-processing with the SBW means combining the NGLW with SBW and treating the combined stream for disposal as TRU waste. While it is clear that a dedicated on-site facility is not cost effective, as compared to using the commercial suppliers, re-use or adaptation of a suitably sized facility that supported the SBW treatment may be a viable option, since the capital costs of the facility could be considered sunk costs. It will be important to continue to consider the treatment of NGLW as the SBW treatment facility design develops. For instance, if a SBW treatment option is selected that provides the necessary capabilities for NGLW treatment in a cost-effective manner, it should be located so that the facility is not isolated from the rest of INTEC after the TFF is closed.

The start of segregation of NGLW (September 2005) used in this study was based on a mandate from DOE-ID that no new waste be introduced into the TFF after that date. That mandate and the final waste classification of the SBW (TRU or HLW) are the reasons that drive the segregation of NGLW. If the SBW should be determined to be HLW, the segregation of the NGLW is recommended from both an economic and regulatory perspective. If the SBW is clearly determined to be TRU waste and the NGLW is TRU or there are no regulatory concerns regarding mixing of the TRU SBW and non-TRU NGLW, there is no reason to segregate NGLW at all. Conversely, it is not recommended that segregation of NGLW start earlier than 2005 because the capacity of the WM100, WM-101, and WM-102 storage tanks would be exceeded, requiring a much 
earlier implementation of the commercial process (the SBW treatment facility would not be available yet).

There are, of course, risks associated with the proposed approach. Some of these risks and their mitigation strategies are discussed below.

The first risk, which is applicable to any management scheme, is that waste characterization, particularly solids concentration and characteristics, is not available. Changes in the composition of the liquid or solids could seriously impact the design of treatment systems. This risk can be mitigated by sampling and characterizing the NGLW (liquid and solids) in a timely fashion. This characterization must be completed early enough to allow the equipment design and procurement to be accomplished in a timely manner.

Another risk is that the recommended approach of co-processing NGLW with SBW involves mixing two waste classifications. The NGLW will probably be mixed low-level waste (MLLW) while the SBW is a TRU waste or high-level waste (HLW). Mixing these streams and producing a (slightly) greater quantity of TRU waste may be considered poor management practice and rejected by stakeholders, even though it is clearly cost-effective and has no impact on the disposal site performance. If the SBW is determined to be HLW, the mixing of non-HLW and HLW will almost certainly be rejected.

The mitigation strategy for this risk is to use the commercial vendor to process the inventory of NGLW generated from 2005 through 2011 separately as MLLW. The decision to adopt this strategy must be made with sufficient lead time that the commercial supplier can develop his process, procure any equipment needed to support the special NGLW needs, and mobilize in the field before the storage capacity of the WM-100, WM-101, and WM-102 tanks is exceeded. Certain facility and infrastructure modifications will also be needed from the INEEL, as well as application for and approval of the necessary environmental permits, and time must be allocated to perform these tasks.

There is also a risk that the commissioning of SBW treatment facility could be delayed for any number of reasons, such that the capacity of the NGLW storage tanks is reached. The mitigation strategy is the same as the previous one, in that the commercial supplier can be employed if sufficient lead-time is provided.

It is possible that the generation rate of NGLW could be substantially greater than currently estimated. The mitigation strategies for this risk depend, to a large extent, on the cause of the increase. Obviously, if a new mission (or re-vitalization of the old reprocessing mission) were to develop, entire new waste management processes would be warranted. If the increase in liquid waste were due to a stricter requirement for "clean closure" of the INTEC facilities, implying great use of decontamination fluids, the schedule for closure of facilities could be driven by the waste treatment capabilities. If other drivers for the closure schedule were identified, a new treatment facility (or adaptation of the SBW treatment facility) could resolve the problem. 
Finally, the tanks that have been proposed as storage tanks for NGLW are currently operated under interim status (RCRA Part A permits) and are included in a Part B application. The tanks also may require a WIR determination so they can be managed as other than HLW. If the tanks should fail to be permitted (unlikely) or be determined to be HLW (also unlikely), the VES-WM-100, VES-WM-101, and VES- WM-102 tanks could not be used for storing NGLW.

Managing the NGLW must be closely integrated with other operations at INTEC and in particular the ITFP. The SBW treatment and tank closure activities that are part of the ITFP could significantly affect the NGLW management approach. The technology option selected for NGLW treatment may have an impact on how NGLW is managed during the SBW treatment campaign as well as afterwards. Changes in the SBW treatment schedule would affect the NGLW management. The schedule and scope of the ITFP tank closure activities must be considered when siting the NGLW treatment system to ensure that access to the NGLW storage tanks is possible after the TFF is closed. 


\section{CONTENTS}

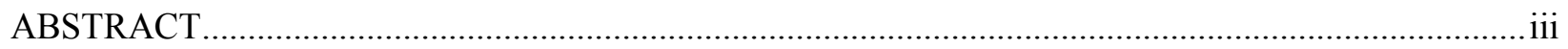

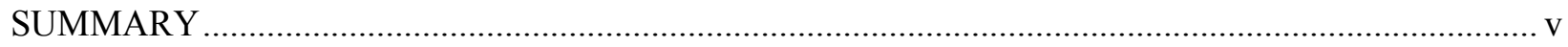

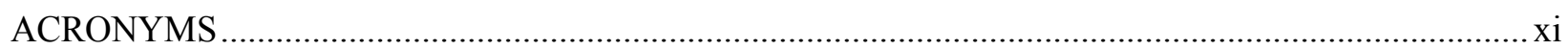

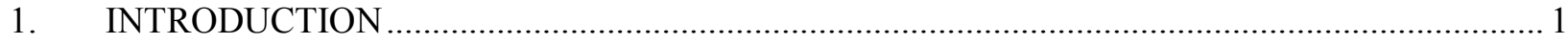

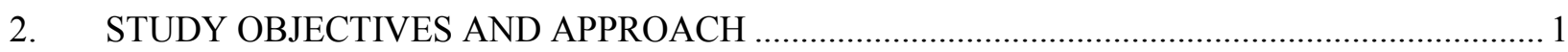

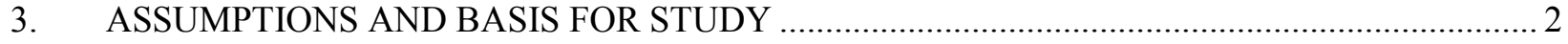

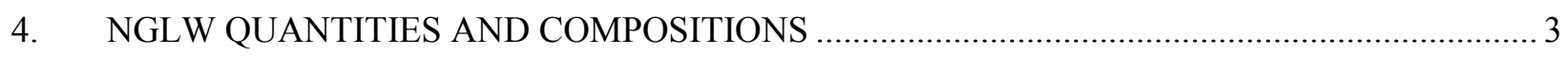

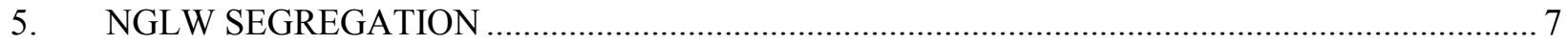

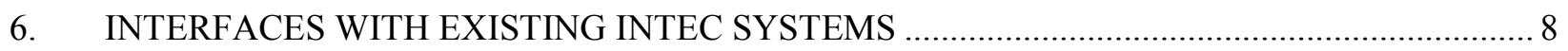

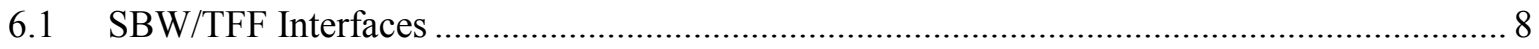

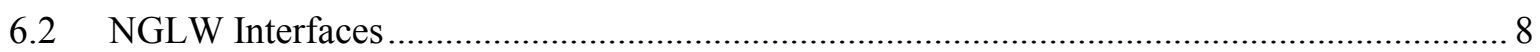

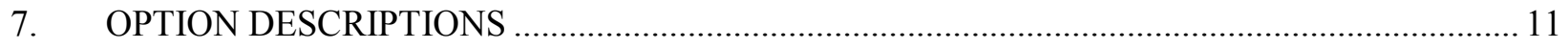

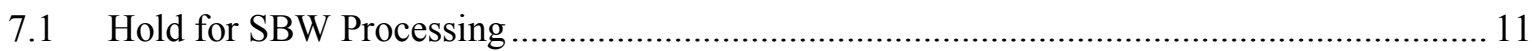

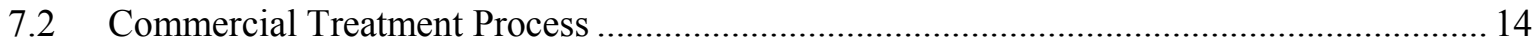

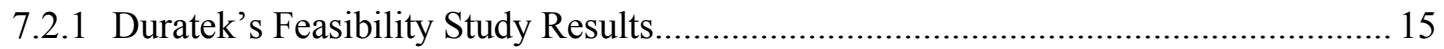

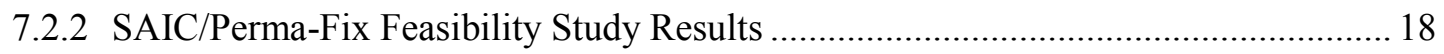

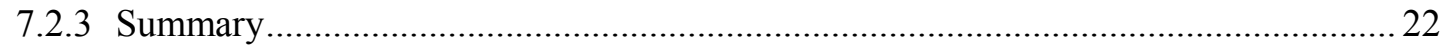

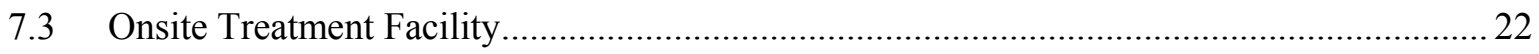

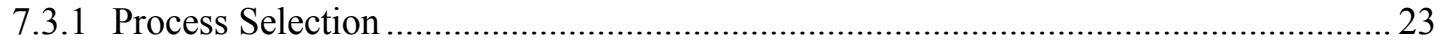

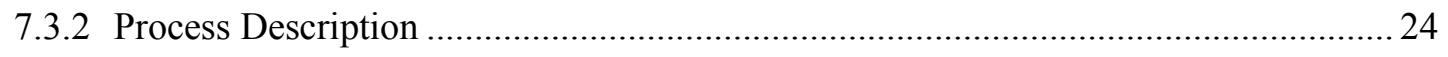

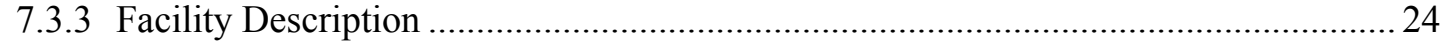

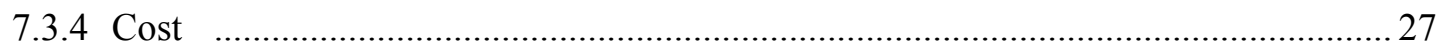

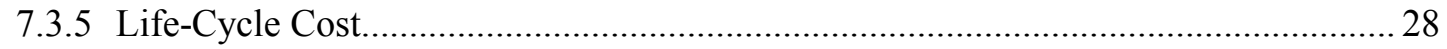

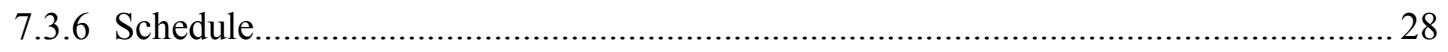

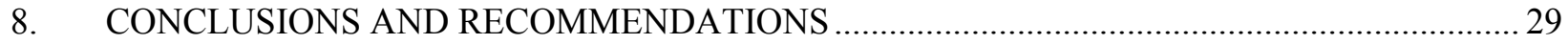

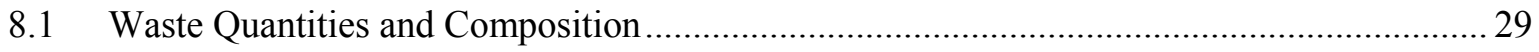

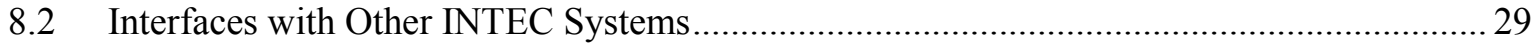

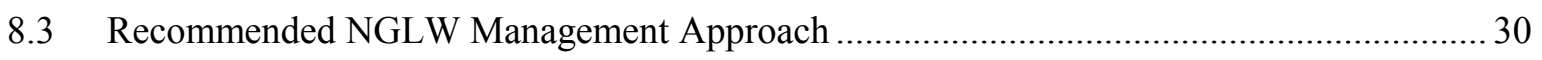

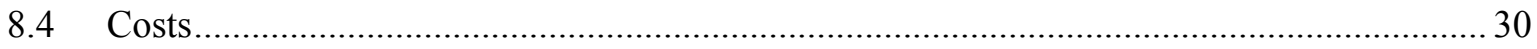




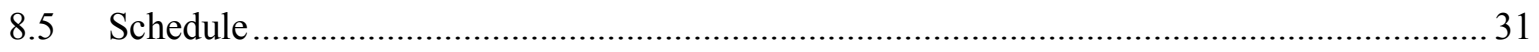

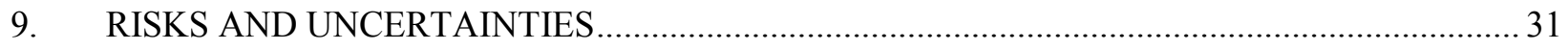

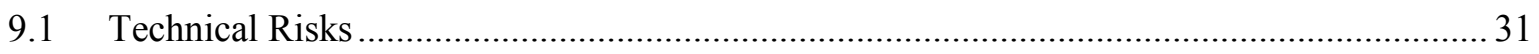

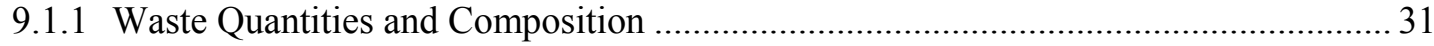

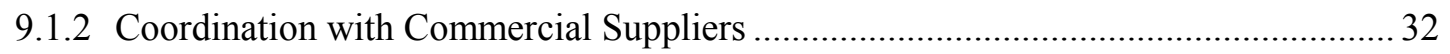

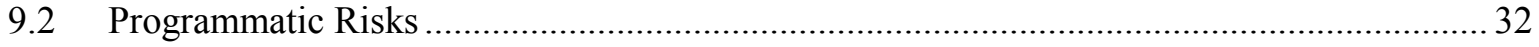

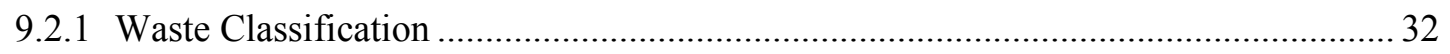

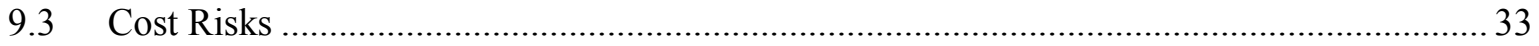

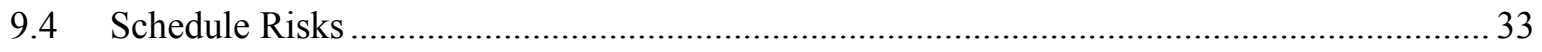

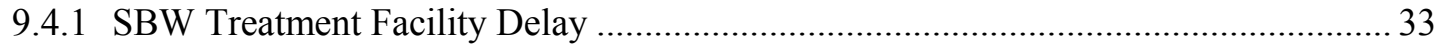

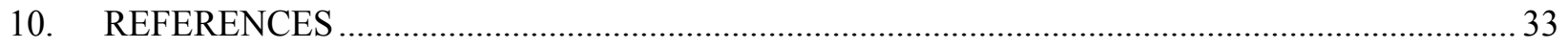

Appendix A - NGLW Composition Estimates ……............................................................................ A1

Appendix B - NGLW Generation and Disposal Cost Analysis ...........................................................

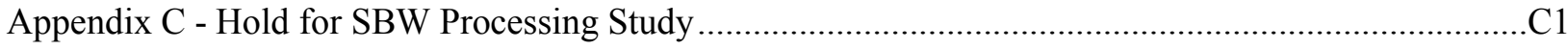

Appendix D - Comercial Process Feasibility Studies .............................................................................. D1

Appendix E - On-site NGLW Treatment Facility Study ......................................................................

\section{FIGURES}

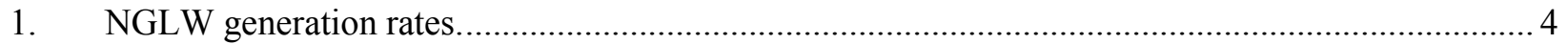

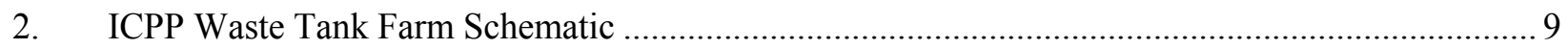

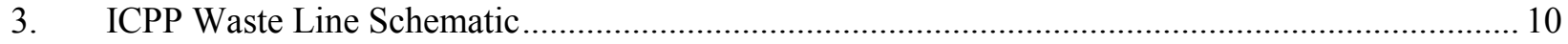

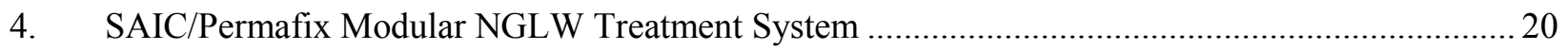

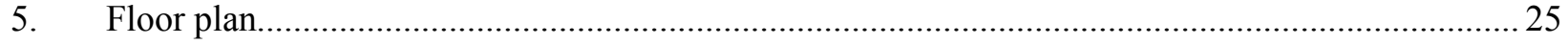

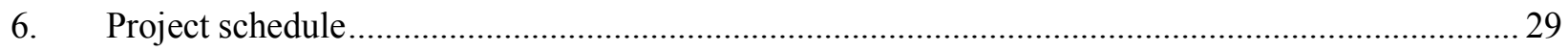

TABLES

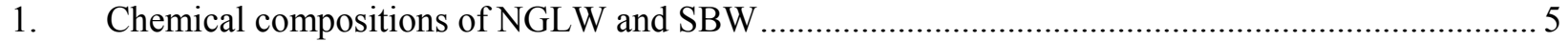

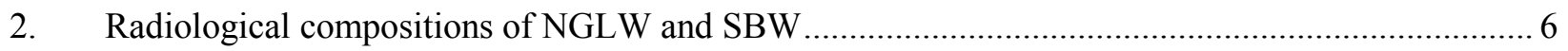

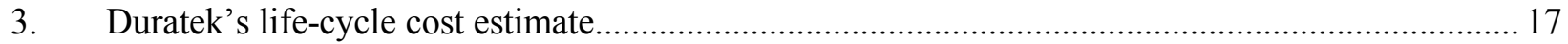

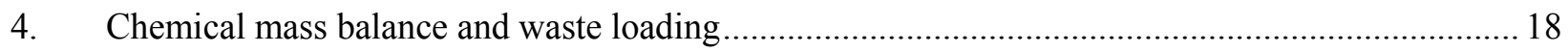

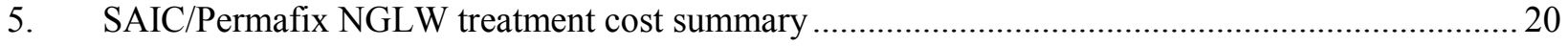

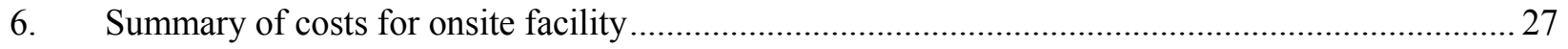




\section{ACRONYMS}

ALARA as low as reasonably achievable

BBWI Bechtel BWXT Idaho, LLC

BNFL British Nuclear Fuels, Ltd.

BWXT BWX Technologies, Inc.

CFR Code of Federal Regulations

$\mathrm{CH} \quad$ contact handled

CPP Chemical Processing Plant

CY calendar year

DOE U.S. Department of Energy

DOE-ID U.S. Department of Energy Idaho Operations Office

ES\&H/QA Environment, Safety, and Health/Quality Assurance

ETS Evaporator Tank System

EXT external

FAST Fluorinel Dissolution Process and Fuel Storage

FDP fluorinel dissolution process

FY fiscal year

HEPA high-efficiency particulate air (filter)

HLLWE high-level liquid waste evaporator

HLW high-level waste

HVAC heating, ventilating, and air conditioning

INEEL Idaho National Engineering and Environmental Laboratory

INTEC Idaho Nuclear Technology and Engineering Center

ITFP Idaho Tank Farm Project

LDR land-disposal restrictions

LET\&D liquid effluent treatment and disposal

LLC Limited Liability Company 


$\begin{array}{ll}\text { LLW } & \text { low-level waste } \\ \text { MLLW } & \text { mixed low-level waste } \\ \text { NGLW } & \text { newly generated liquid waste } \\ \text { NWCF } & \text { New Waste Calcining Facility } \\ \text { ORR } & \text { Operational Readiness Review } \\ \text { P\&V } & \text { pump and valve } \\ \text { PED } & \text { Project Engineering and Design } \\ \text { PEWE } & \text { process equipment waste evaporator } \\ \text { PLC } & \text { programmable logic control } \\ \text { PPE } & \text { personal protective equipment } \\ \text { RAL } & \text { Remote Analytical Laboratory } \\ \text { RFP } & \text { request for proposal } \\ \text { RCRA } & \text { Resource Conservation and Recovery Act } \\ \text { WIPP } & \text { Waste Isolation Pilot Plant } \\ \text { RH } & \text { remote handled } \\ \text { SAIC } & \text { Science Applications International Corporation } \\ \text { WBW } & \text { sodium-bearing waste } \\ \text { SBWTF } & \text { SBW Treatment Facility } \\ \text { SNF } & \text { spent nuclear fuel } \\ \text { TFF } & \text { Tank Farm Facility } \\ \text { TPC } & \text { total project cost } \\ \text { TRU } & \text { transuranic } \\ \text { WNiversal Extraction }\end{array}$




\section{Newly Generated Liquid Waste Processing Alternatives Study}

\section{INTRODUCTION}

Facilities at the Idaho Nuclear Technology and Engineering Center (INTEC) (formerly Idaho Chemical Processing Plant) were used from 1953 to 1992 to reprocess spent nuclear fuel (SNF) to recover fissile uranium. Liquid high-level waste (HLW) was generated as part of the reprocessing of the SNF and stored in large underground tanks in the Tank Farm Facility (TFF) at INTEC. In 1963, the Waste Calcining Facility (WCF) was commissioned to convert the liquid HLW to a dry granular form for safer long-term storage. The WCF operated until 1982 when the New Waste Calcining Facility (NWCF) was commissioned and completed treatment of the HLW in 1998.

In addition to the HLW generated as a direct result of fuel reprocessing, other activities at INTEC produced additional radioactive liquid wastes. These wastes have been designated as sodium-bearing waste (SBW) due to the presence of higher concentrations of sodium compounds. The Idaho National Engineering and Environmental Laboratory (INEEL) stored the SBW in the TFF tanks. About 225,000 gallons of this SBW was also converted to calcine in NWCF before that facility was shut down in 2000. Currently, about 900,000 gallons of SBW remain in the TFF.

A 1995 Settlement Agreement between the State of Idaho, Department of Energy (DOE), and U.S. Navy requires that treatment of the SBW be completed by December 31, 2012. The current plan is to manage this SBW as mixed transuranic (TRU) waste (rather than HLW) and to dispose of it in the Waste Isolation Pilot Plant (WIPP), which is the designated disposal site for defense-related TRU waste. The Idaho Tank Farm Project (ITFP) is responsible for treatment of the SBW, closure of the TFF, and remediation of contaminated soil in the area of the TFF. Part of the ITFP is the design and construction of the SBW Treatment Facility (SBWTF), which will treat the 900,000 gallons of SBW to meet the waste acceptance criteria (WAC) for WIPP.

Ongoing operations at INTEC (filter leach, fuel storage facility operations, decontamination efforts, and laboratory drains from CPP-601) continue to generate liquid wastes. These wastes have been designated as newly generated liquid waste (NGLW). Typically, these wastes are generated in large volumes and with low levels of radioactive contamination. At present, NGLW is concentrated in the INTEC evaporator systems, process equipment waste evaporator (PEWE), and liquid effluent treatment and disposal (LET\&D) system. The concentrated NGLW is added to the existing volume of liquid wastes currently stored in the TFF tanks. These tanks do not meet all the requirements of the Resource Conservation and Recovery Act (RCRA) for hazardous waste storage tanks, and the TFF is currently operated under interim status. For this and other reasons, the DOE Idaho Operations Office (DOE-ID) has mandated that addition of NGLW to the TFF cease by September 30, 2005.

\section{STUDY OBJECTIVES AND APPROACH}

The main objective of this study was to evaluate options for treating and disposing of the NGLW at INTEC to determine the most cost-effective method. First, quantities and characteristics of the NGLW had to be defined. Estimates were made using very limited data regarding the quantities and schedule for generation, the chemical composition, and the radioactive contaminants, because the NGLW has not been generated yet. As noted above, the normal operations at INTEC provide substantial volume reduction of the NGLW by concentrating it using the existing evaporator systems. The study evaluated the 
concentration and disposal costs to assess whether the concentration efforts were cost-effective. The study then evaluated three approaches for treating and disposing of NGLW:

- $\quad$ Hold for SBW processing

- Use a commercial treatment process

- $\quad$ Design and construct a dedicated facility at INTEC for treating NGLW.

The first option involves storing NGLW in RCRA-compliant tanks until the facility for treating SBW becomes available for treating the NGLW. It is assumed that the process that is used to treat the SBW will be directly applicable to the NGLW, which is somewhat different in chemical and radiological composition.

The second option subcontracts the treatment and disposal of the NGLW to a supplier of these types of services. Some new construction and infrastructure modifications will be required to support these operations. The process equipment, materials, and operating personnel will be supplied by the subcontractor.

In the third option, a feasibility study would be developed for a facility to be designed and constructed at INTEC to treat the NGLW and ship it offsite for disposal.

These options were estimated and compared to determine the most cost-effective approach. These cost analyses also include the disposal costs, since these costs are significant contributors to the overall life-cycle cost for the treatment and disposal of NGLW.

\section{ASSUMPTIONS AND BASIS FOR STUDY}

The management of liquid waste at INTEC is a complex issue, technically and programmatically. Some technical data are not available and some programmatic issues have yet to be resolved. Therefore, the following assumptions were made to establish the bases for this study and allow the effort to proceed.

Programmatic assumptions:

- $\quad$ SBW is mixed TRU and will be treated to meet the appropriate waste acceptance criteria. (Note that the program basis at the time the study was started considered [conservatively] the SBW to be HLW.)

- $\quad$ Transfers of NGLW to the tank farm 300,000 gallon tanks will cease after September 2005, as mandated by DOE-ID.

- NGLW is not HLW.

- $\quad$ SBW treatment will be complete by December 31, 2011. (The program basis at the start of the study was that the SBW treatment would not be complete until 2016.)

- $\quad$ Environmental permits will be obtained by the INEEL. 
Technical assumptions:

- $\quad$ NGLW generation rates are assumed to be as shown in Reference 1, which is included in this report as Appendix A. Note that non-INTEC streams are not currently treated at INTEC and this practice was assumed to continue.

- $\quad$ NGLW chemical and radiological compositions are as described in Appendix A.

- $\quad$ Evaluations shall include the costs of transportation to and disposal at the final disposal site.

- $\quad$ The PEWE and LET\&D evaporators will be operable through 2020.

Cost assumptions:

- $\quad$ The PEWE and LET\&D capital costs are sunk costs.

- $\quad$ Disposal of contact handled (CH) TRU at WIPP costs $\$ 32,000$ per HalfPACT.

- $\quad$ Disposal of remote handled (RH) TRU at WIPP costs $\$ 203,000$ per RH canister.

Other less-significant assumptions, not listed here, were also needed during the development of the study and are identified in the individual sections or supporting documents.

\section{NGLW QUANTITIES AND COMPOSITIONS}

NGLW is generated in dilute form from a number of sources at INTEC. Some of these sources are facilities that previously dealt with HLW (such as NWCF) and a Waste Incidental to Reprocessing (WIR) determination may be required regarding them. A WIR determination identifies waste streams that would otherwise be managed as HLW due to the source of generation or concentration of radionuclides but that can properly be managed as either TRU or LLW.

Currently liquid waste from non-INTEC sources is not being processed at INTEC. It is assumed that this practice will continue.

The volume of the dilute NGLW is quite large and typically is reduced by processing the dilute solution through the INTEC evaporator systems. These estimated dilute and concentrated NGLW volumes are shown, by year, in Figure 1 . These volumes do not include the liquid wastes generated as a result of tank closure operations because those wastes will be cycled through the INTEC evaporator systems and returned to the Tank Farm Facility for processing as SBW.

An analysis was performed to determine whether treating and disposing of the NGLW in the concentrated form was more cost effective than treating and disposing of it in the dilute form. This analysis (Appendix B), which included the estimated operating cost of the evaporator systems, indicated that processing the NGLW as concentrated waste was clearly more cost effective. The capital cost of the evaporators was considered to be a sunk cost in this analysis. The decommissioning cost of the evaporators was also not included because that cost will be incurred regardless of whether the evaporators are used for NGLW concentration or not. For the dilute volume, the cost of transportation and disposal at Hanford (using published disposal costs) was estimated to be about $\$ 43.8 \mathrm{M}$. For the concentrated case, the cost of evaporation was estimated to be $\$ 18.3 \mathrm{M}$ and the transportation and disposal cost was estimated to be $\$ 5.3 \mathrm{M}$, for a total cost of $\$ 23.6 \mathrm{M}$. Thus, the cost savings of concentrating the NGLW is 
\$20.2M. Note that this analysis did not include the operating costs of the treatment facility, which may be less for the concentrated case because there is so much less volume to manage.

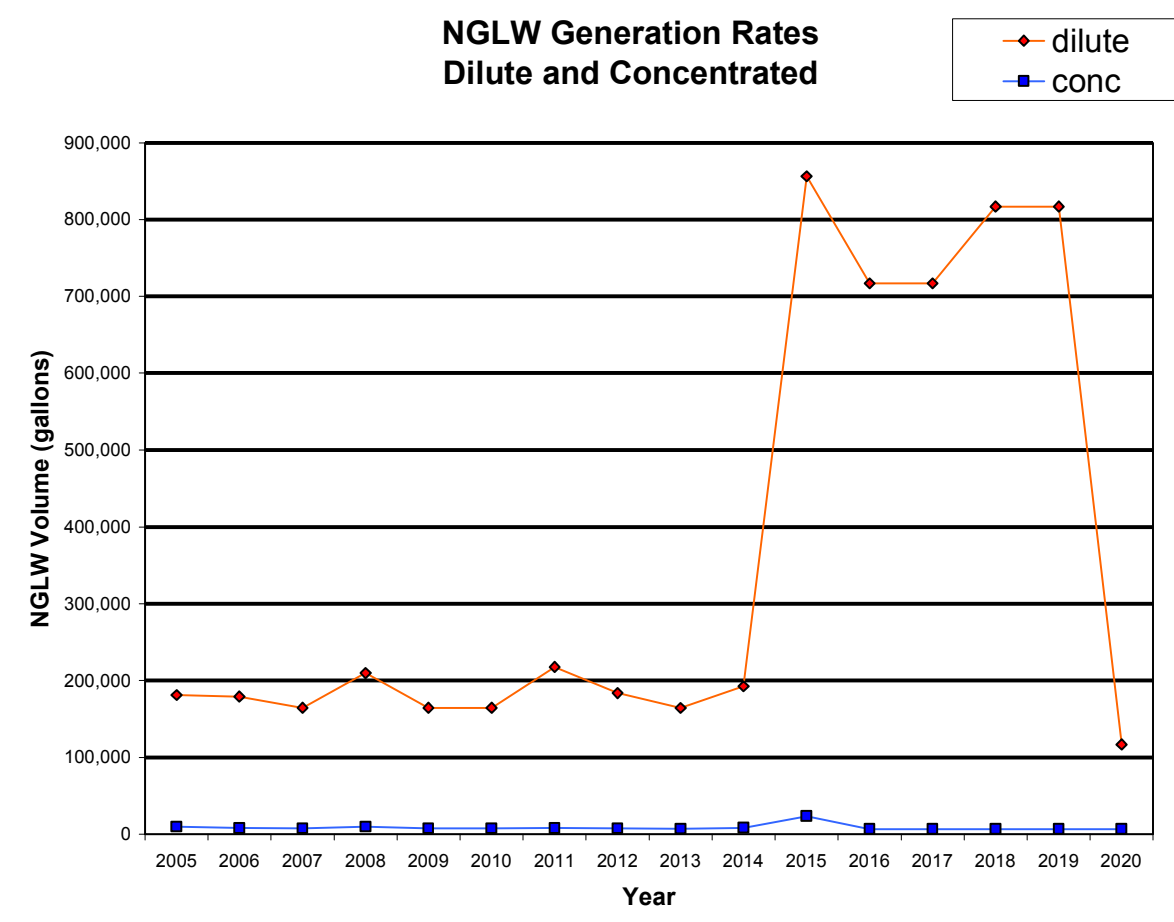

Figure 1. NGLW generation rates.

At some time in the future (assumed to be after 2020), the existing evaporators will almost certainly have to be replaced or significantly upgraded. Those capital costs would need to be considered in the overall treatment and disposal cost analysis for those future wastes. It is likely that the cost of new evaporator systems could not be justified by the treatment and disposal cost savings that would result from volume reduction of the limited volumes of NGLW that are currently predicted after 2020 . However, there are so many uncertainties in trying to predict waste generation rates that far in the future that it is not reasonable to draw any conclusions regarding those new systems at this time.

Estimating the chemical and radiological compositions of the NGLW is even more problematic than estimating the NGLW quantities. Both are very dependent on the operations being performed and only very limited data are available. Given that caveat, the properties of the NGLW can be summarized as follows. Chemically, the NGLW streams are typically more acidic (in the range of $4.5 \mathrm{M}$ to $5.0 \mathrm{M}$ acid) than the SBW (in the range of $1 \mathrm{M}$ to $3 \mathrm{M}$ ) and contain less dissolved solids than SBW.

These chemical differences will significantly affect the performance of some of the process technologies that have been identified as potential solutions for SBW. Radiologically, the concentrated NGLW is less active than SBW. The TRU concentration of NGLW is lower than the SBW concentration by a factor of 30, resulting in an average TRU activity (not to be confused with the TRU waste classification) in the NGLW liquid of about $15 \mathrm{nCi} / \mathrm{g}$, which is much less than the lower limit of $100 \mathrm{nCi} / \mathrm{g}$ needed for a waste to be considered TRU waste. Thus, the NGLW would be managed as mixed low-level waste (MLLW) if these estimated concentrations are, in fact, correct. The Cs-137 concentration of the average NGLW liquid is at least an order of magnitude less than that of the SBW. The average chemical compositions of NGLW and SBW liquids are shown in Table 1. The average radiological compositions of the NGLW and SBW liquids are shown in Table 2. 
Table 1. Chemical compositions of NGLW and SBW.

\begin{tabular}{|c|c|c|}
\hline $\begin{array}{c}\text { Chemical Element or } \\
\text { Compound }\end{array}$ & $\begin{array}{l}\text { NGLW Concentration } \\
\text { (moles/liter) }\end{array}$ & $\begin{array}{l}\text { SBW Concentration } \\
\text { (moles/liter) }\end{array}$ \\
\hline $\mathrm{H}+$ & $4.79 \mathrm{E}+00$ & $2.24 \mathrm{E}+00$ \\
\hline $\mathrm{Al}$ & $9.27 \mathrm{E}-02$ & $9.27 \mathrm{E}-02$ \\
\hline $\mathrm{Sb}$ & $3.94 \mathrm{E}-05$ & 2.64E-05 \\
\hline As & 4.14E-04 & $2.14 \mathrm{E}-04$ \\
\hline $\mathrm{Ba}$ & $5.14 \mathrm{E}-05$ & 7.92E-05 \\
\hline $\mathrm{Be}$ & $2.33 \mathrm{E}-06$ & $3.51 \mathrm{E}-06$ \\
\hline B & $1.03 \mathrm{E}-03$ & $1.91 \mathrm{E}-02$ \\
\hline $\mathrm{Cd}$ & 8.82E-05 & 4.77E-03 \\
\hline $\mathrm{Ca}$ & $3.60 \mathrm{E}-03$ & $5.37 \mathrm{E}-02$ \\
\hline $\mathrm{Cr}$ & $6.11 \mathrm{E}-04$ & 4.94E-03 \\
\hline Co & 5.97E-06 & $9.17 \mathrm{E}-05$ \\
\hline $\mathrm{Cs}$ & $8.20 \mathrm{E}-07$ & $1.45 \mathrm{E}-05$ \\
\hline $\mathrm{Cu}$ & $2.41 \mathrm{E}-04$ & 8.47E-04 \\
\hline $\mathrm{Fe}$ & $1.20 \mathrm{E}-03$ & $2.26 \mathrm{E}-02$ \\
\hline $\mathrm{Pb}$ & $6.73 \mathrm{E}-05$ & $2.26 \mathrm{E}-03$ \\
\hline $\mathrm{Hg}$ & $1.16 \mathrm{E}-04$ & $3.10 \mathrm{E}-03$ \\
\hline $\mathrm{Mn}$ & $3.24 \mathrm{E}-03$ & $1.56 \mathrm{E}-02$ \\
\hline $\mathrm{Ni}$ & $2.66 \mathrm{E}-04$ & $3.46 \mathrm{E}-03$ \\
\hline K & $6.85 \mathrm{E}-03$ & $1.71 \mathrm{E}-01$ \\
\hline $\mathrm{Se}$ & $1.03 \mathrm{E}-06$ & 4.69E-05 \\
\hline $\mathrm{Ag}$ & $8.11 \mathrm{E}-06$ & $1.46 \mathrm{E}-05$ \\
\hline $\mathrm{Na}$ & $6.57 \mathrm{E}-02$ & $1.59 \mathrm{E}+00$ \\
\hline $\mathrm{Tl}$ & $5.76 \mathrm{E}-07$ & $2.00 \mathrm{E}-05$ \\
\hline $\mathrm{U}$ & $4.65 \mathrm{E}-05$ & 4.32E-04 \\
\hline $\mathrm{V}$ & $6.08 \mathrm{E}-06$ & $3.70 \mathrm{E}-04$ \\
\hline $\mathrm{Zn}$ & $1.31 \mathrm{E}-03$ & $1.46 \mathrm{E}-03$ \\
\hline $\mathrm{Zr}$ & $9.93 \mathrm{E}-04$ & $1.16 \mathrm{E}-02$ \\
\hline $\mathrm{Cl}$ & $1.95 \mathrm{E}-03$ & $2.55 \mathrm{E}-02$ \\
\hline $\mathrm{F}$ & $2.61 \mathrm{E}-02$ & 8.32E-02 \\
\hline $\mathrm{SO}_{4}$ & 8.30E-03 & $5.28 \mathrm{E}-02$ \\
\hline $\mathrm{NO}_{3}$ & $5.14 \mathrm{E}+00$ & $5.93 \mathrm{E}+00$ \\
\hline $\mathrm{PO}_{4}$ & $1.01 \mathrm{E}-04$ & 7.73E-03 \\
\hline TOC $\mathrm{g} /$ liter & $3.80 \mathrm{E}+00$ & $6.35 \mathrm{E}-01$ \\
\hline Undissolved solids g/liter & $2.71 \mathrm{E}+00$ & $2.61 \mathrm{E}+00$ \\
\hline
\end{tabular}


Table 2. Radiological compositions of NGLW and SBW.

\begin{tabular}{|c|c|c|}
\hline Isotope & $\begin{array}{c}\text { NGLW } \\
\text { Concentrations } \\
(\mathrm{Ci} / \text { liter })\end{array}$ & $\begin{array}{c}\text { SBW } \\
\text { Concentrations } \\
(\mathrm{Ci} / \text { liter }) \\
\end{array}$ \\
\hline $\mathrm{H}-3$ & $1.09 \mathrm{E}-07$ & $2.10 \mathrm{E}-05$ \\
\hline Co-60 & $1.07 \mathrm{E}-07$ & $6.59 \mathrm{E}-05$ \\
\hline Sr-90 & $1.60 \mathrm{E}-03$ & $4.11 \mathrm{E}-02$ \\
\hline Y-90 & $1.60 \mathrm{E}-03$ & 4.11E-02 \\
\hline $\mathrm{Nb}-94$ & $5.57 \mathrm{E}-08$ & $1.04 \mathrm{E}-06$ \\
\hline Tc-99 & $2.67 \mathrm{E}-07$ & $1.16 \mathrm{E}-05$ \\
\hline Ru-106 & $4.23 \mathrm{E}-11$ & $8.44 \mathrm{E}-06$ \\
\hline Rh-106 & $4.23 \mathrm{E}-11$ & $8.44 \mathrm{E}-06$ \\
\hline Sb-125 & 5.37E-08 & 4.19E-05 \\
\hline I-129 & $2.59 \mathrm{E}-07$ & $8.04 \mathrm{E}-08$ \\
\hline Cs-134 & $1.85 \mathrm{E}-08$ & $9.64 \mathrm{E}-05$ \\
\hline Cs-137 & $1.81 \mathrm{E}-03$ & 4.89E-02 \\
\hline Ba-137m & $1.70 \mathrm{E}-03$ & 4.60E-02 \\
\hline Ce-144 & $1.11 \mathrm{E}-11$ & N/A \\
\hline Pr-144 & $9.23 \mathrm{E}-12$ & N/A \\
\hline Eu-152 & $7.18 \mathrm{E}-08$ & $3.07 \mathrm{E}-06$ \\
\hline Eu-154 & $3.12 \mathrm{E}-06$ & $2.25 \mathrm{E}-04$ \\
\hline Eu-155 & 8.32E-07 & 1.79E-04 \\
\hline U-232 & $1.42 \mathrm{E}-10$ & 6.33E-09 \\
\hline U-234 & $1.61 \mathrm{E}-08$ & $1.07 \mathrm{E}-06$ \\
\hline U-235 & $2.26 \mathrm{E}-08$ & $2.82 \mathrm{E}-08$ \\
\hline U-236 & $1.25 \mathrm{E}-09$ & 4.49E-08 \\
\hline U-238 & $1.04 \mathrm{E}-09$ & $3.12 \mathrm{E}-08$ \\
\hline $\mathrm{Np}-237$ & $1.08 \mathrm{E}-07$ & $1.92 \mathrm{E}-06$ \\
\hline $\mathrm{Pu}-238$ & $1.80 \mathrm{E}-05$ & $6.36 \mathrm{E}-04$ \\
\hline Pu-239 & $2.66 \mathrm{E}-06$ & $7.85 \mathrm{E}-05$ \\
\hline $\mathrm{Pu}-240$ & $4.26 \mathrm{E}-07$ & $9.21 \mathrm{E}-06$ \\
\hline $\mathrm{Pu}-241$ & $6.27 \mathrm{E}-06$ & $3.72 \mathrm{E}-04$ \\
\hline $\mathrm{Pu}-242$ & 4.69E-10 & $1.68 \mathrm{E}-08$ \\
\hline Am-241 & $2.77 \mathrm{E}-06$ & $8.17 \mathrm{E}-05$ \\
\hline Total TRU & $2.40 \mathrm{E}-05$ & $8.07 \mathrm{E}-04$ \\
\hline
\end{tabular}


Additional detail regarding the chemical and radiological composition of the NGLW is available in Reference 1, which is included in Appendix A. As noted there, this NGLW chemical composition does not include the LET\&D bottoms (12M nitric acid with very slight radioactive contamination), which would increase the acid concentration even more. This stream was excluded because it could be recycled by using it in place of fresh acid in decontamination activities (with some minor piping modifications).

\section{NGLW SEGREGATION}

DOE-ID has mandated that no new waste be stored in the TFF 300,000-gallon tanks after 2005 and that mandate was taken as a requirement in this study. Rather than continue to mix the NGLW with the SBW currently stored in the TFF, the NGLW is planned to be diverted to storage in three existing tanks, VES-WM-100, VES-WM-101, and VES-WM-102. These tanks provide limited storage capacities of about 18,000 gallons each and using them for storage of concentrated NGLW complicates the liquid waste management operations somewhat. Nonetheless, it appears that, given the present generation estimates for NGLW, it is feasible to segregate the NGLW in these tanks. These waste generation rates are based on current estimates and do not include the impact of future waste minimization efforts. The proposed storage capacity is able to handle the estimated waste generation without additional minimization efforts. Continued waste minimization activities can, however, be cost effective and provide additional margin in storage capacity to accommodate generation rates in excess of those estimated. It should also be noted that without the continued scrutiny of the waste minimization efforts, the waste generation may tend to creep higher.

One advantage of storing NGLW separate from the SBW is that it allows the NGLW to be treated without regard for the waste classification of the SBW. While the NGLW from HLW facilities may require some type of WIR determination (either citation or evaluation) regarding its management, it is reasonable to assume that is will be managed as LLW. SBW, on the other hand, could be considered TRU waste or HLW. An evaluation has recently been performed that indicates that SBW is waste incidental to reprocessing (WIR) and should be managed as TRU waste rather than HLW. However, the underlying DOE Order regarding radioactive waste management is being challenged in court and could potentially affect this WIR determination for SBW, resulting in a HLW classification for the SBW (although this is not considered likely). Segregation of the NGLW certainly makes economic sense if the SBW were to be determined to be HLW. However, if the SBW is determined to be TRU, it is economically preferable to treat and dispose of the NGLW with the SBW, and has no impact on the repository performance. Still, it could be considered bad management practice to generate more TRU, even though it can be processed cost effectively. Finally, if the NGLW is later determined to be TRU (rather than LLW as currently estimated) or if mixing of the NGLW and TRU SBW is deemed acceptable, the NGLW inventory can always be mixed with the SBW prior to processing the SBW.

The disadvantage of storing the NGLW separate from the SBW is that it complicates the tank farm management.

On the other hand, an advantage of mixing NGLW with SBW is that it leaves the VES-WM-100, VES-WM-101, and VES-WM-102 tanks available for other, more convenient, liquid waste management scenarios. Another advantage (if it can be considered an advantage) is that once mixed, the waste classification of the NGLW is moot because it can never be separated from the SBW again.

In conclusion, given the uncertainty in the classification of the SBW and the fact that it is feasible to separate NGLW, it appears there is no compelling reason to overturn the restriction on adding NGLW to the TFF after 2005 at this point. 


\section{INTERFACES WITH EXISTING INTEC SYSTEMS}

The options for treatment of NGLW must consider the changing configuration of INTEC as the existing facilities are closed. Of particular concern to the management of the NGLW are the processing of the SBW, the closure of the TFF tanks, and closure of other existing facilities such as NWCF. These activities may directly impact both the composition and quantity of NGLW that will eventually be generated and the ability to route liquid waste (newly generated or SBW) around the plant.

The waste transfer paths typically used in moving liquid waste around INTEC are briefly described below. Figures 2 and 3 show a simplified diagram of the waste line routing throughout INTEC.

\subsection{SBW/TFF Interfaces}

SBW (stored in the 300,000-gallon tanks in the TFF) is normally routed to the NWCF Blend and Hold Tanks in CPP-659 (the NWCF facility) via Valve Box B-11, located at the east end of the main header that runs east-west between the 300,000-gallon tanks. The Blend and Hold Tanks are used as feed tanks for either the calciner or the NWCF-Evaporator Tank System (ETS), (formerly designated the high-level liquid waste evaporator [HLLWE]) both of which are located in CPP-659. The calciner and the ETS are not operated concurrently.

Continued access to CPP-659 will be required to support tank closure operations. The dilute liquid waste that will be generated as part of the tank closure activities will, after allowing solids to settle, be concentrated in the HLLWE. The concentrated liquid (bottoms) will be returned to the TFF via B-11. The condensed overheads from the HLLWE, which are much less radioactively contaminated, will be collected in one of the NWCF sump tanks (NCM-122) before being transferred to the PEWE (and eventually LET\&D) via Valve Boxes D-6 and C-37.

After all eleven 300,000-gallon tanks are closed the access through B-11 to CPP-659 will be eliminated. This will eliminate access to the HLLWE unless piping modifications are made inside NWCF. Given the current INTEC mission, eliminating access to the HLLWE should not be a major concern because the sources of highly radioactive waste streams should be eliminated as well.

As noted previously, the SBW must be treated by 2012. Several options are under consideration for treating the SBW and some of them involve design and construction of a new treatment facility. If the SBW treatment facility is expected to provide treatment of NGLW after closure of the TFF, its availability to the sources of NGLW must be addressed. If the new facility were to be located east of the TFF, it would access the 300,000-gallon tanks through Valve Box B-11. If it were to be located north of the TFF, access to the TFF would likely be through Valve Box B-7. Both of these valve boxes connect to the TFF and would be closed with the TFF. In these cases, the new SBW treatment facility would be isolated from the rest of the plant by the closure of the TFF, unless new waste lines were installed around the TFF, which is likely to be an expensive proposition.

\subsection{NGLW Interfaces}

NGLW will be generated throughout INTEC. The locations of the major sources of NGLW are:

- $\quad$ NWCF (decon, filter leach, calciner closure)

- $\quad$ Tank Farm sumps and wells

- $\quad$ CPP-601 laboratory drains

- $\quad$ Flourinel Dissolution Process and Fuel Storage (FAST) Facility operations. 
Figure 2. ICPP Waste Tank Farm Schematic 
Figure 3. ICPP Waste Line Schematic 
The current plan is to divert the concentrated NGLW to Tanks VES-WM-100, -WM-101, and -WM-102 after September 2005 in compliance with a DOE-ID mandate that liquid waste addition to the 300,000-gallon TFF tanks cease by 2005. As shown in Figures 2 and 3, these tanks can be reached from any source of NGLW without passing through the valve boxes to be directly affected by the TFF closure activities (generally, the "B" valve boxes), although some routes may be more tortuous than others.

NWCF liquid wastes have been transferred from the sump tanks via a path from valve box DVB D-4 to DVB C-37 to DVB C-40 to DVB C-30 and finally to VES WM-100. Liquid can be transferred as needed between the three WM tanks.

The tank farm sumps and wells can be transferred to either PEWE or the WM-100 tank via the various valve boxes located within the TFF. As the tanks and valve boxes are closed, the need for these types of transfers will be eliminated.

The other major sources of liquid waste at INTEC are the CPP-601 building drains and the operations at CP-666, the FAST facility. Both these sources can be transferred to WM-100 from the "west side" of INTEC without interaction with the TFF systems.

Finally, the PEWE bottoms can be transferred from either VES-WL-101 or VES-WL-111 to WM-100 via DVB C-37, DVB C-40, and DVB C-30. Although this transferred has not actually been performed yet, INTEC Operations personnel are confident that the transfer can be made.

Based on this analysis, the NGLW treatment system (either a dedicated facility or the mobile units) should be located near CPP-604 and Valve Box C-40 to allow access to the WM-100, WM-101, and WM-102 tanks. If the facility is located north of the tank farm, several of the valve boxes inside the TFF (A-7, B-1, B-3, B-4, and B-7 or B-11) and their associated transfer lines would have to remain in operation as long as the NGLW continued to be generated at INTEC, or a new liquid transfer line would have to be provided.

As noted, this segregation of NGLW will require additional documentation regarding the waste classification of the various streams. Streams from facilities that have generated or treated HLW in the past, such as those from NWCF, may require a WIR determination as to whether they must be managed as HLW, TRU, or LLW. It is likely that most of the streams would easily be determined to be LLW by citation but the effort may still be necessary. Other streams, such as those from the fuel storage basins, are clearly not HLW and do not require additional evaluation. Tanks VES-WM-100, -WM-101, and -WM-102 may also require a WIR determination since they had previously been used in HLW service.

\section{OPTION DESCRIPTIONS}

\subsection{Hold for SBW Processing}

This option for managing the NGLW is intended to examine storing the waste in RCRA permitted tankage until the facility for processing SBW is available to treat the NGLW. At that time, the contents of these tanks would be processed through the SBW facility. Then, depending on the process technology selected for the SBW treatment, the facility may be able to accommodate intermittent operation with NGLW as needed.

Three programmatic assumptions that directly affect this option have changed considerably since the study started. These assumptions and their impacts are discussed below.

- $\quad$ The SBW was considered to be HLW. Given the strict waste form requirements and anticipated high cost of disposal at the monitored geologic disposal facility for HLW, it was clearly cost 
effective to separate the NGLW (assumed to be non-HLW) from the SBW (HLW) as required by DOE Order 435.1.

- $\quad$ Processing of SBW would not be complete until 2018. The change in the date for completing processing of the SBW was significant because the volume of waste generated between 2005 (start of separation of NGLW and SBW) and 2018 would exceed the capacity of the WM-100, WM-101, and WM-102 tanks that had been identified as potential storage vessels.

- $\quad$ SBW would be treated by direct vitrification and that facility would continue operation with calcine treatment. This continued use of the facility would allow future NGLW treatment to be "piggy-backed" on a much larger operation.

This option actually seemed quite promising when the SBW was to be treated by direct vitrification. For example, the NGLW treatment would be scheduled immediately after a melter change-out (which was expected to occur every two years) so that it be processed through a "clean" melter. This would eliminate concerns that the NGLW product might be contaminated by the higher radiological composition of the HLW (liquid or calcine) or that the product might be designated as HLW. In effect, the capital cost of the facility would be treated as a sunk cost and the NGLW treatment would only need to address operating and other associated costs. The capability of treating future NGLW was also provided because the direct vitrification facility was expected to continue operations on calcine after the SBW campaign was completed.

Early in this study, a design for additional RCRA compliant storage was developed and a cost estimate was made. The combined storage capacity of these new tanks would provide the additional volume over that already provided by WM-100, WM-101, and WM-102. This volume was calculated to be a total of 86,000 gallons, to support collection of NGLW through 2020 (recall that the start date for SBW processing was thought to be much later than currently estimated). Various tank configurations were considered to both contain the estimated NGLW volume and provide the additional contingency storage capacity required by RCRA. It was determined that using three 50,000-gallon tanks was the optimum configuration. The cost for these tanks and the associated facility and subsystems was estimated to be $\$ 29.3 \mathrm{M}$. The facility drawings and cost estimate are provided in Appendix C.

Given the recent changes in the program basis, this option must be reconsidered. First, the current start date for SBW processing (2010) means that no new tankage is required above that provided by WM-100, WM-101, and WM-102 to accommodate the NGLW generated by that date. Second, the processing scenario should be determined. At the start of the SBW campaign, two paths for treating NGLW are possible. One is to mix the NGLW with the SBW and produce a single TRU waste stream for disposal at WIPP. The other is to process the NGLW separately, which will result in a mixed LLW product that will probably be disposed of at Hanford, and will certainly have to meet different waste acceptance criteria. The concern here is whether a non-TRU stream (NGLW) can be added to a TRU stream (SBW) resulting in a larger TRU product stream. Third, the SBW facility has no continuing mission after completing the SBW treatment, as the direct vitrification option did, in that the direct vitrification facility was expected to continue operating on calcine. While it may be cost effective to use the SBW facility to process the NGLW accumulated through 2011 (the estimated end of SBW processing), it may not be cost effective to maintain the SBW facility in its entirety to support NGLW processing after 2011. So, the evaluation must consider how much of the SBW facility must be maintained to support the future NGLW processing and compare that to the total cost for the other NGLW processing options (on site facility or commercial supplier). These points are addressed in the following paragraphs.

Capacity of Storage Tanks. No new tanks are required to accommodate the expected NGLW volume by 2010 and the same capacity is adequate for future operations (at least, through 2020). It is 
possible to provide additional new storage so that the interval between processing campaigns might be reduced and the SBW plant used to better capacity at longer intervals. However, this approach is not viable, in that:

- $\quad$ At the current estimated NGLW generation rates, the full scale SBW facility would only need to be operated every 10 years or so, and the maintenance costs during the down time would far exceed any capital cost advantage.

- $\quad$ Design and construction of new tanks, even if they could be economically justified in the very long term, is not likely to be accepted by either DOE or the State of Idaho.

Given the current NGLW generation rates, the WM-100, WM-101, and WM-102 tanks are sufficient and no additional storage capacity need be considered.

Processing Scenario. There are two cases to be considered in evaluating the processing scenarios: processing NGLW separately in the SBW facility, or mixing it with the SBW and then processing the mixture. It should be noted that the NGLW volume is only a small percentage (less than 7\%) of the SBW volume.

The first issue is related to the process technology. The chemical differences between NGLW and SBW (in particular the acid and dissolved solids concentrations) will probably require substantially different process flow sheets, even for the same general technology. The radiological differences also impact this strategy. The waste forms produced by the candidate SBW processing technologies will meet the WAC for the Waste Isolation Pilot Plant (WIPP) (a deep geologic disposal site) but not the WAC for Hanford (a near surface disposal site), which must be met if NGLW is processed by itself as MLLW. The chemical differences and waste form issue argue strongly for "co-processing" the NGLW and SBW, from a process technology standpoint.

The second issue is the cost of treatment and disposal. The operating cost of treating the NGLW is probably very nearly the same for either case. In fact, the cost of treating the NGLW separately is likely to be higher, due to issues such as the need to maintain separate waste qualification programs for different disposal sites. For the purposes of this analysis, the treatment costs are assumed to be equal for either case. The estimates for the disposal costs at WIPP are currently being evaluated. Based on the WIPP disposal costs for CH-TRU of $\$ 32,000$ per HalfPACT, as documented in a telecon between James Murphy of the INEEL and Harold Johnson of the Carlsbad Area Office, the cost of disposing of the grouted NGLW volume as CH-TRU is estimated to be $\$ 6.8 \mathrm{M}$, while the cost for disposing of the same volume as MLLW at Hanford is estimated to be \$5.3M. If an option resulted in an RH-TRU waste form for the NGLW, the cost of disposal at WIPP would be $\$ 203,000$ per RH-TRU canister, according to the same telecon. Typically, the SBW treatment options that produce RH-TRU result in much higher volume reductions than would be experienced for a grouted product. Assuming (conservatively) a factor of 10 volume reduction, the volume of NGLW RH-TRU waste would be about $1700 \mathrm{ft}^{3}$ with a corresponding disposal cost of $\$ 11.2 \mathrm{M}$. At these rates, it appears that disposal of the NGLW as MLLW would be more cost effective. However, these WIPP disposal costs have recently been disputed as being too high. According to Reference 4, the cost for disposing of the combined volume of SBW and NGLW at WIPP is about $\$ 10 \mathrm{M}$, for either $\mathrm{CH}$ or $\mathrm{RH}$. The $\mathrm{CH}$ disposal cost is less than the RH cost on a unit volume basis but the process options that produce RH-TRU waste typically provide much higher volume reductions than the $\mathrm{CH}$ processes, so the total disposal cost in either the $\mathrm{CH}$ or $\mathrm{RH}$ case is about the same. Simply applying the ratio of the NGLW volume and the total waste volume to the disposal cost results in an approximate incremental cost for disposal of the NGLW at WIPP of $\$ 650,000$, when the NGLW is co-processed with SBW.

Given these disposal costs, it is clearly cost effective to co-process the NGLW and SBW. 
SBW Continuing Mission. Assessing this issue is difficult because the design for the SBWTF has not been finalized and the cost of using the SBWTF for future treatment of NGLW (after the SBW campaign is complete) cannot be quantitatively evaluated at this time. In fact, there are several processing options that are currently being considered. Some of the options involve a single large facility, sized to handle the entire SBW volume in three years or less. The single large facility options are much too large for intermittent treatment of the NGLW. Maintenance costs during the interim would far exceed the actual cost of treating the NGLW. Others employ additional smaller facilities for treatment of secondary wastes streams. These smaller facilities may be more suited to the throughput required for NGLW treatment and may, in fact, be applicable (with minor modifications) to the NGLW treatment. For instance, if a small grout facility were to be required for the SBW option (such as the scrub blowdown treatment for the calciner option), that facility might be used effectively for future treatment of NGLW. A final decision on this point cannot be made until the SBWTF design is finalized. Clearly, the management of NGLW must be coordinated with the ITFP with respect to waste generation, facility closure on liquid waste transfer, and design of the SBWTF, as applicable.

\subsection{Commercial Treatment Process}

This option for treating the NGLW involved subcontracting commercial suppliers to bring their equipment and personnel onsite at intervals to process the accumulated NGLW. In an effort to obtain better estimates of the cost of this option, funding was allocated to support development of feasibility studies by qualified suppliers. A search was conducted for firms that advertised the capability to treat radioactive wastes at the generator's site. Requests for proposals (RFPs) were sent to six of these firms:

- $\quad$ IT Group

- $\quad$ Permafix Environmental Services (Permafix) and Science Applications International Corporation (SAIC)

- $\quad$ British Nuclear Fuels, Ltd (BNFL)

- $\quad$ Duratek Services

- U.S. American Ecology

- $\quad$ Nuclear Fuel Services.

The RFPs asked these suppliers to develop feasibility studies based on processes that they determined would be applicable to the treatment and disposal of the NGLW and that they had experience with. Two firms, Duratek and Permafix/SAIC, responded positively to the request for proposals and were awarded subcontracts to develop the feasibility studies and cost estimates for the NGLW treatment. Note that these studies are not, and were not intended to be, firm bids to do the work. As both suppliers noted, better characterization data will be required for the NGLW before process designs can be confirmed and firm price quotes developed.

The NGLW treatment scenario studied consisted of a vendor providing mobile equipment that can be set up at INTEC, operated, disassembled, and removed. NGLW treatment would occur in campaigns approximately every five years beginning in 2010 and finishing in 2020. This periodic timing corresponds to anticipated NGLW accumulations of about 50,000 gallons for each treatment campaign. The study assumed that the NGLW liquid is hazardous low-level waste (mixed LLW) and that utilities such as water, steam, and electrical power are available at the work site. Permitting and/or permit modifications were to be provided by the INEEL.

It should be emphasized that the basis for these feasibility studies was processing of the NGLW liquid. The impact of the undissolved solids (if any) is not considered in these designs because the 
characterization of quantity and composition of the undissolved solids in NGLW is even more problematic than characterization of the liquid. If the undissolved solids were to be present in a "worst case" concentration, the dose associated with the product would be much more than could reasonably dealt with in a mobile system as currently envisioned for the commercial units. Based on the estimated worst case undissolved solids quantities and compositions, the calculated dose from the grouted product exceeds $1.5 \mathrm{R} / \mathrm{hr}$. This is obviously beyond the capacity of mobile systems with minimal shielding and would require substantially different handling techniques. The quantity and characteristics of the undissolved solids in the NGLW need to be determined as soon as possible after the segregation of the NGLW begins, if not before.

It should also be noted that the costs presented in this section are those typically associated with construction (and operation) and do not include a number of additional costs that will be incurred, such as environmental, safety, and health costs like safety assessments of the design and operation, environmental permitting, modifications and additions to INTEC infrastructure, etc.

\subsubsection{Duratek's Feasibility Study Results}

The Duratek proposal is included in Appendix D.

\subsubsection{Process Selection}

Duratek evaluated several methods for treating NGLW. (See Reference 2 in Appendix D.) The evaluation included development of project criteria, evaluation of the treatment methods against the criteria, and selection of the preferred option. Objective and subjective criteria were developed based on the functional requirements and constraints imposed upon the study. Objective criteria included categories such as equipment and operating costs, technology maturity, size, capacity, effluents, schedule restraints, final waste form, permits needed, and ownership (patents). Subjective criteria include categories such as licensability, regulatory, and public and DOE acceptance.

The "optimal" treatment process system was determined through an options evaluation and selection process conducted by several subject matter experts. The options under consideration were ranked using evaluation criteria. Each criterion was given a weight between 5 and $15 \%$, depending on its importance to the project. A range of raw scores ( 1 to 5, with 1 the worst and 5 the best) reflecting the potential merits of each NGLW treatment alternative was assigned for each alternative to each criterion. The total score for each option was then calculated by multiplying the raw score and the weights.

Duratek examined three NGLW solidification scenarios:

- In-Container Batch Solidification

- $\quad$ External to Container Batch Solidification

- External to Container Continuous Solidification.

In-Container Batch Solidification was selected because it provides advantages in the areas of equipment cost and operational simplicity when compared to the other two alternatives. The total score for this option was 4.66. The next highest score was 4.09 for the External to Container Continuous Solidification option and the lowest score was 3.4 for the External to Container Batch Solidification alternative.

\subsubsection{Process Description}

Given the estimated NGLW chemical composition, Duratek decided to use a sludge-based formula to develop preliminary material balances. This formula consists of $38.5 \mathrm{wt} . \%$ raw waste, $55.6 \mathrm{wt} . \%$ 
Portland Type I cement and 5.9 wt.\% hydrated lime. The basis for selecting this formula was to provide the highest waste loading that would produce a stabilized product meeting the disposal facility's waste acceptance criteria (WAC). Duratek stresses the fact that treatability studies are required before a formula is actually selected.

NGLW is transferred to a waste-conditioning tank where it is neutralized to a $\mathrm{pH}$ of 10 with lime. Duratek selected lime because concentrated caustic (30 to $50 \mathrm{wt} \%$ ) freezes at relatively high temperatures (30 to $60^{\circ} \mathrm{F}$ ) and the bicarbonate forms for calcium and sodium involve carbon dioxide formation.

The neutralized waste is metered into a $160-\mathrm{ft}^{3}$ waste solidification container equipped with disposable mixing blades. Cement is added to the top of the container and mixed with the waste. Duratek estimates a $78 \%$ volume increase but emphasizes that testing is necessary to establish an acceptable formula for treating the NGLW. Based upon this waste loading, 191 filled containers will be produced for each batch of 50,000 gallons of NGLW.

\subsubsection{Equipment}

The process equipment will be located inside a temporary radiation shield consisting of cement blocks and stainless steel doors. The primary components include the Waste Solidification Liner (equipped with disposable internal mixing blades), the Fill Head Assembly, Hydraulic System, Conveying System, Control Panel and the Waste Conditioning Tank.

The Waste Solidification Liner specified is a Duratek model made of polyethylene that meets the requirements for 10 CFR 61 . The liner contains disposable mixer blades that are used to blend the waste with the stabilizing reagents. The liner is located within a shield to reduce radiation exposure to operating personnel.

The Fill Head Assembly is used to control the waste feed and chemical additions during the stabilization/solidification process. The assembly contains a hydraulic motor that connects to the mixing blade shaft within the liner along with piping for dewatering and instrumentation for monitoring liner level and temperature. A television camera and light for remote closed circuit viewing of the liner internals are also located in the assembly.

The hydraulic system is located in the low-radiation area and provides the power to the hydraulic motor located in the Fill Head Assembly. The mixer speed is controlled with this unit and the mixer rotation can be reversed if necessary.

The dry stabilizing agents are delivered to the site in a delivery trailer equipped with a self-contained conveying system that loads the dry reagents into a bin. The dry reagents are fed from the bin to the Fill Head Assembly with a screw conveyor.

The Control Panel provides the operator with all the controls, measurements, and alarms necessary for the safe remote operation of the system. The television monitor, temperature and weight indicators, and switches for the valves and process equipment are located on the panel. The control panel is located in a trailer designed to be a control room and has storage for spare parts.

The Waste Conditioning Tank is used to receive the waste from INTEC operations and is equipped with a mixer for mixing lime with the waste for $\mathrm{pH}$ adjustment.

The area required for the Duratek process is approximately $65 \mathrm{ft} \times 85 \mathrm{ft}$. This includes the staging area for 10 empty or filled liners. 


\subsubsection{Radiological Assessment}

Duratek evaluated the radiation exposure associated with the NGLW inventory provided by BBWI. The estimated exposure rates and shielding requirements were evaluated using Microshield $\AA$.

The Waste Conditioning Tank requires shielding to maintain radiation exposures as low as reasonably achievable (ALARA). Once the waste is stabilized the self-shielding property of the grouted product eliminates the need for extra shielding.

Duratek's assessment indicates that the stabilized waste will not require extra shielding for off-site shipment unless the NGLW produced in 2015 (NWCF decon waste) is not blended with the other NGLW sources.

\subsubsection{Life-Cycle Cost Estimates}

In order to facilitate cost comparisons for each alternative studied, both vendors were instructed to report costs in FY 2002 dollars and use an annual escalation rate of 3\% for NGLW treatment campaigns in calendar years 2010, 2015 and 2020. Table 3 lists Duratek's cost breakdown for the study.

Table 3. Duratek's life-cycle cost estimate.

\begin{tabular}{lrrrr}
\hline \multicolumn{1}{c}{ Cost } & CY 2010 & CY 2015 & CY 2020 & \multicolumn{1}{c}{ Life Cycle } \\
\hline Equipment & $\$ 2,514,966$ & & & $\$ 2,514,966$ \\
Liner & $\$ 824,289$ & $\$ 955,576$ & $\$ 1,107,775$ & $\$ 2,887,640$ \\
Cement & $\$ 43,690$ & $\$ 50,648$ & $\$ 58,715$ & $\$ 153,053$ \\
Lime & $\$ 2,827$ & $\$ 3,278$ & $\$ 3,800$ & $\$ 9,905$ \\
Premobilization/Maintenance & $\$ 251,497$ & $\$ 291,554$ & $\$ 337,990$ & $\$ 881,041$ \\
Transportation & $\$ 38,664$ & $\$ 44,822$ & $\$ 51,961$ & $\$ 135,447$ \\
Set Up/Start Up & $\$ 118,988$ & $\$ 137,940$ & $\$ 159,910$ & $\$ 416,838$ \\
D\&D/Demobilization & $\$ 194,437$ & $\$ 225,406$ & $\$ 261,307$ & $\$ 681,150$ \\
Labor & $\$ 360,459$ & $\$ 417,871$ & $\$ 484,427$ & $\$ 1,262,757$ \\
Materials & $\$ 295,587$ & $\$ 342,667$ & $\$ 397,245$ & $\$ 1,035,499$ \\
Waste Disposal & $\$ 485,461$ & $\$ 562,783$ & $\$ 652,419$ & $\$ 1,700,663$ \\
\hline Total & $\$ 5,130,865$ & $\$ 3,032,544$ & $\$ 3,515,549$ & $\$ 11,678,958$ \\
\hline
\end{tabular}

Duratek estimates the total life cycle cost for treating the NGLW to be $\$ 11.7 \mathrm{M}$ with a contingency of \$0.5M. At BBWI's direction, the waste disposal costs are based upon Hanford's current disposal unit price for contact handled waste $\left(\$ 19.50 / \mathrm{ft}^{3}\right)$. If the waste is remote handled, the disposal cost increases to $\$ 120 / \mathrm{ft}^{3}$. This condition adds approximately $\$ 8.8 \mathrm{M}$ to the life cycle cost. Duratek's shielding calculations indicate that the treated NGLW in the liner will be contact handled. However, if the waste remains Category 3 , then the disposal cost is $\$ 63 / \mathrm{ft}^{3}$. The extra charge is for putting the liner into a high-integrity container. This scenario adds $\$ 3.8 \mathrm{M}$ to the life-cycle cost.

It should be noted that the costs shown here represent the equivalent of the construction and operation. Care should be used when comparing these costs to the total project cost (TPC) estimate provided for the onsite facility. The TPC includes additional costs not included in the above such as waste characterization, technology verification, interfaces to existing INTEC systems, and INEEL site management. 


\subsubsection{SAIC/Perma-Fix Feasibility Study Results}

The SAIC/Perma-Fix team proposed a system that is based upon Perma-Fix's experience with treating acidic waste streams. The system proposed is a batch solidification process that uses a separate mixer that is external to the waste container. (See Reference 3 in Appendix D.)

\subsubsection{Process Description}

The NGLW treatment system proposed by SAIC/Perma-Fix includes neutralization with caustic followed by stabilization with dry reagents.

The process equipment is modularized and skid mounted for transporting to the site. Each skid is designed with secondary containment to collect any leaks or spills. In order to control emissions, all process equipment is connected to a HEPA filtered process ventilation system that maintains a negative pressure within the equipment as well as within a temporary enclosure used to house the process.

After evaluating several neutralization reagents and associated equipment requirements, the SAIC/Permafix team decided to use $50-\mathrm{wt} \%$ caustic to increase the NGLW $\mathrm{pH}$ to 10 prior to stabilization. The neutralization process includes a chiller system to control the heat of reaction during the neutralization process.

\subsubsection{Material Balance and Process Throughputs}

Table 4 lists a range of treatment additives required to neutralize and solidify the NGLW. A range is provided due to variability in the waste. This information was submitted to "bound" the proposed treatment process until NGLW characterization and treatability studies are completed to finalize the treatment recipe.

Table 4. Chemical mass balance and waste loading.

\begin{tabular}{cc}
\hline Parameter & Unit Basis (Per gallon raw NGLW) \\
\hline Mass Raw NGLW to Treat & $9.0-10.5 \mathrm{lbs}$ \\
$50 \%$ NaOH for Neutralization & $3-4 \mathrm{lbs}$ \\
Stabilization Reagent A & $0.4-0.5 \mathrm{lbs}$ \\
Stabilization Reagent B & $0.6-1.0 \mathrm{lbs}$ \\
Reagent B Scavenger & $0.3-0.5 \mathrm{lbs}$ \\
Stabilized Waste Mass Subtotal & $13.3-16.5 \mathrm{lbs}$ \\
Stabilized Waste Loading & $68 \%-64 \%$ \\
Stabilized Waste Volume & $1.3-1.5 \mathrm{gal}$ \\
Solidification Agent & $17.5-50 \mathrm{lbs}$ \\
Cement Modifier & $2.9-5.0 \mathrm{lbs}$ \\
Solidified Waste Mass Total & $33.7-71.5 \mathrm{lbs}$ \\
Solidified Waste Loading & $26 \%-15 \%$ \\
Solidified Waste Volume & $0.3-0.7 \mathrm{cu} \mathrm{ft}$ \\
Final Vol Relative to Initial Vol & $225 \%-500 \%$ \\
\hline
\end{tabular}

The proposed NGLW treatment system was sized to process 71,000 gallons of NGLW within 31/2 months. This capacity was chosen so the NGLW treatment could avoid operating impacts due to inclement weather. 
In order to compare costs with the other vendor, the life-cycle costs discussed later in this report are based upon treating 50,000 gallons per campaign.

\subsubsection{System Description}

The SAIC/Permafix treatment system has the following components:

- $\quad$ NGLW storage tank that stores NGLW as received from the Tank Farm Facility

- Neutralization tank and ancillary equipment for neutralizing the NGLW in a batch-type process

- An NGLW accumulation tank to store the neutralized NGLW prior to solidification

- A ribbon mixer where the neutralized NGLW is mixed with solidification reagents in a batch type mode

- $\quad$ Bulk cement storage silo

- Off-gas unit that provides negative pressure to the process equipment and enclosure. The off-gas is HEPA filtered prior to atmospheric discharge.

The integrated system will operate in a batch-processing mode. The NGLW is neutralized in 300-gallon increments and sent to the accumulation tank. The neutralized NGLW is added to the ribbon mixer in 90 to170-gallon batches. Cement and cement modifiers (if necessary) are added to the mixer and blended with the waste for about 30 minutes. The mixed grout is discharged to a waste bin located underneath the mixer. The filled waste bins are conveyed to an accumulation area where they will be allowed to cure for about 48 hours.

\subsubsection{Process Control System}

Process control and monitoring functions will be made using a programmable logic control (PLC)-based controller. The PLC integrates the instrumentation and control equipment for each unit operation in the NGLW treatment system. Process parameters such as pressures, temperatures, $\mathrm{pH}$, flows, and liquid levels will be monitored and recorded by the process control system. The PLC will also archive pertinent NGLW treatment information that is necessary to qualify the waste for disposal.

\subsubsection{NGLW Treatment System Layout and Requirements}

Figure 4 is an isometric cut-away view of the treatment process located within a containment structure. This containment building is estimated to be $48 \times 48 \mathrm{ft}$. The containment building is modular in design to allow simplified setup and disassembly. Enclosed cargo containers will be used for reagents, personal protective equipment (PPE), and other miscellaneous materials.

The filled B-12 bins will be stored over secondary containment while the grout cures to a solid form. The containment building is sized to accommodate storage of $20 \mathrm{~B}-12$ bins. The bin containing the cured grout will be transported to an outside staging area to await shipment to the Hanford facility. The outside staging area is sized to have $350 \mathrm{~B}-12$ bins.

This is based upon a 35-day turnaround time for obtaining analytical results and certifying the waste for shipment to Hanford.

Estimated space necessary for the modular NGLW treatment process and container staging area is $250 \times 300 \mathrm{ft}$. 


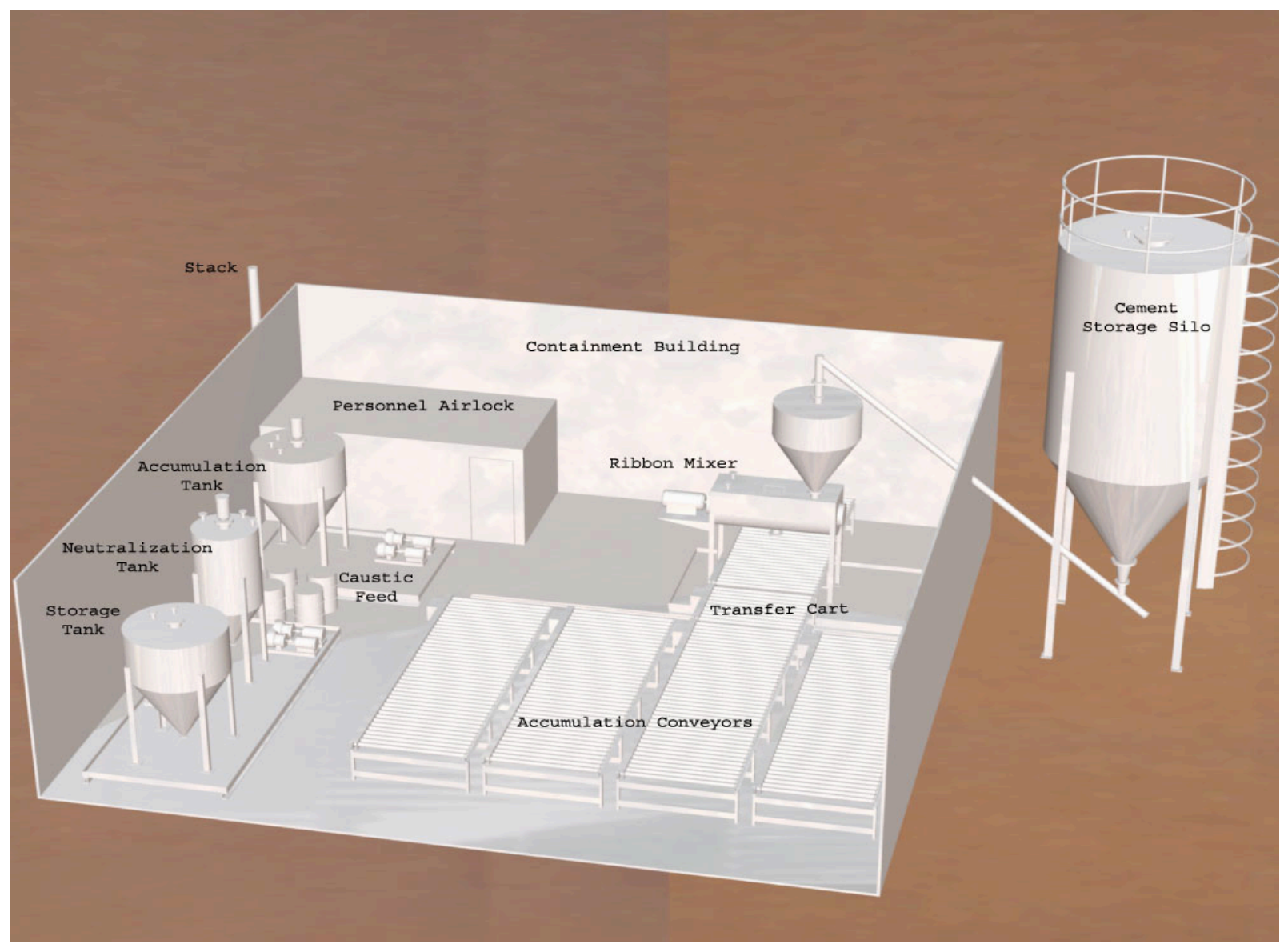

Figure 4. SAIC/Permafix Modular NGLW Treatment System.

\subsubsection{Life-Cycle Costs}

Costs associated with treatment of the NGLW were based on three individual treatment campaigns occurring in years 2010, 2015, and 2020. The baseline cost estimate was developed using 2002 dollars and escalated $3 \%$ annually for the out-year treatment campaigns.

Cost estimates, including escalation, for each treatment campaign are listed in Table 5.

Table 5. SAIC/Permafix NGLW treatment cost summary.

\begin{tabular}{lrrrr}
\hline \multicolumn{1}{c}{ Cost Item } & \multicolumn{4}{c}{ Cost (in thousands) } \\
& FY 2010 & FY 2015 & FY 2020 & Total \\
\hline Capital Equipment ${ }^{\mathrm{a}}$ & $\$ 1,595$ & $\$ 100$ & $\$ 100$ & $\$ 1,795$ \\
Operations and Maintenance & & & & \\
Labor & $\$ 559$ & $\$ 648$ & $\$ 751$ & $\$ 1,958$ \\
Materials & $\$ 963$ & $\$ 1,116$ & $\$ 1,294$ & $\$ 3,373$ \\
System Operations Testing and Operational & & & & \\
$\begin{array}{l}\text { Readiness Review } \\
\text { Labor }\end{array}$ & $\$ 315$ & $\$ 365$ & $\$ 423$ & $\$ 1,103$
\end{tabular}




\begin{tabular}{lrrrr}
\hline \multicolumn{1}{c}{ Cost Item } & \multicolumn{3}{c}{ Cost (in thousands) } \\
& FY 2010 & FY 2015 & FY 2020 & Total \\
\hline Disposal and Transportation $^{\text {b }}$ & $\$ 623$ & $\$ 723$ & $\$ 838$ & $\$ 2,184$ \\
Equipment Decon/Dismantle (labor only) & $\$ 79$ & $\$ 91$ & $\$ 106$ & $\$ 276$ \\
Mobilization & $\$ 157$ & $\$ 183$ & $\$ 212$ & $\$ 552$ \\
Subtotal & $\$ 4,291$ & $\$ 3,226$ & $\$ 3,723$ & $\$ 11,240$ \\
Contingency (35\%) & $\$ 1,502$ & $\$ 1,129$ & $\$ 1,303$ & $\$ 3,934$ \\
\hline TOTAL & $\$ 5,793$ & $\$ 4,355$ & $\$ 5,027$ & $\$ 15,175$ \\
\hline $\begin{array}{l}\text { a. Nominal equipment replacement costs of } \$ 100,000 \text { per year in campaigns 2015 and 2020. } \\
\text { b. Disposal and transportation costs include estimated waste certification costs. }\end{array}$ & & \\
\hline
\end{tabular}

A general description of the activities associated with the cost estimate is provided below:

- Capital Costs. These costs include engineering design/supervision, process and containment building procurement, assembly, and acceptance testing. The costs were generated based on rough order of magnitude vendor quotes of conceptualized process equipment.

- $\quad$ Operation and Maintenance Costs. These costs consist of the labor and material costs for performing operational readiness reviews (ORRs), mobilization, system operations testing, NGLW treatment and decontamination/dismantlement. The major operation and maintenance costs are incurred during the NGLW treatment operations. Labor costs were developed based on processing 50,000 gallons of NGLW within a period of $1 \frac{1}{2}$ months with working schedule of 24 hours per day.

- $\quad$ Operational labor costs have been estimated based on the resources required to safely and efficiently operate the treatment system. During the NGLW treatment period, two dedicated crews will staff the treatment facility on a rotating shift schedule (12 hour shifts, 24 hours per day, 7 days per week). The dedicated crew for each shift consists of the following personnel:

- Shift supervisor

- $\quad$ Treatment system operators

- $\quad$ Laborers

- $\quad$ Project management: a full-time project engineer and part-time project manager.

- Materials that will be consumed during treatment operations include:

- $\quad$ Neutralization agents - caustic solution and proprietary reagents A and B

- $\quad$ Portland Cement and cement modifiers (if used)

- Disposal containers-B-12 bins

- $\quad$ Personal protective equipment.

- $\quad$ The ORR provides an independent review of the NGLW treatment system prior to the start of operations. An ORR will be required prior to the initial startup of the treatment system in 2010 and prior to the restarts of the system in 2015 and 2020.

- $\quad$ The Hanford Solid Waste Disposal charges (FY-2002 rates) for disposal of MLLW is $\$ 19.50$ per cubic foot for non-PHMC customers. The total disposal cost was calculated by multiplying this rate times the total volume of grouted NGLW. Based upon a conversation between SAIC and Hanford, 
it is assumed that the stainless steel B-12 bin and grouted NGLW will meet the requirements for a 300-year design life package (i.e., the combination of the container and waste form will qualify as a high-integrity container). No disposal surcharges are expected to apply since there is no remote handling issues or oversized or unusual packing issues.

- Mobilization and setup costs are primarily labor costs associated with assembling the treatment system onsite and configuring the system for system operations testing and the ORR.

\subsubsection{Summary}

Both vendors provided valuable study reports that can be used to evaluate NGLW treatment alternatives. Basically their approaches to resolving the problem are similar with few noteworthy differences. The following is a list of comments relating to the study reports:

- $\quad$ Waste Loading. PermaFix estimates a 125 to $400 \%$ volume increase but emphasizes that testing with actual waste samples is necessary to establish an acceptable formula for treating the NGLW. PermaFix described case histories for stabilizing waste containing high sodium and/or acid. In these cases the waste volume increases were in the range of 225 to $240 \%$. However, in each case, Permafix indicated that chromium was one of the reasons such a low waste loading was necessary. Since NGLW does not have the high Cr levels, it is reasonable to believe that the waste loading is conservatively estimated.

- $\quad$ Waste Loading. Duratek's approach is not as detailed but should work. The issue of meeting land disposal restrictions (LDR) standards for RCRA metals is briefly noted in their study.

- $\quad$ Grout Formulations. Both vendors qualified their grout formulations by stating that treatability studies are required before the grout formulations can be finalized.

- $\quad$ Neutralization Reagent. Duratek recommends using lime, whereas SAIC/Perma-Fix suggests caustic. Lime may not be as efficient in neutralizing the waste as the caustic. However, when grouting the waste this potential disadvantage is offset by the advantage of using calcium based neutralizing reagent versus sodium based. It is more difficult to make a performance grout with waste containing a lot of sodium.

- $\quad$ Neutralization Heat Generation. SAIC/Perma-Fix recommends installing a chiller system to remove the heat of reaction during the neutralization process. Duratek estimates the solution temperature will reach $137^{\circ} \mathrm{F}$. It is unclear if this temperature is problematic with respect to gas emissions.

- $\quad$ Shielding Requirements. Duratek performed a thorough evaluation of the radiation exposure and shielding requirements for their process. The SAIC/Perma-Fix study did not address this issue.

- $\quad$ Project Life-Cycle Costs. Both vendors provided reasonable life-cycle cost estimates. Duratek's cost contingency is too low. If SAIC/Perma-Fix's contingency is used with Duratek's cost estimate, then both cost estimates are comparable. Duratek's process involves fewer waste containers requiring disposal. However, the container disposal costs may be understated if the liners need to be placed into a Hanford culvert high-integrity container. SAIC/Perma-Fix's stainless steel bin and performance grout may meet the criteria for a 300-year package but this needs to be confirmed.

\subsection{Onsite Treatment Facility}

A study was conducted to evaluate technology options, develop a facility design based on the optimum technology, and estimate the cost of this facility. This portion of the study is documented in a feasibility study report, INEEL/EXT-02-01161, which is included as Appendix E. The results of that study are summarized below. 
This development of the onsite concept was very useful, in that it identified additional interfaces, generated additional requirements and highlighted additional areas of concern as the feasibility study was developed in more detail. In general, the vendor studies represent the only the construction and operating costs for those concepts. The onsite facility project includes a number of costs that will be incurred regardless of the procurement approach. This is discussed in more detail in the following sections.

\subsubsection{Process Selection} NGLW.

Several process technologies (listed below) were identified as potential candidates for treating the

- $\quad$ CsIX/Grout. This option filters the NGLW to remove undissolved solids, removes the cesium (Cs) isotopes by ion exchange to reduce the dose from the final product to allow contact handling of the final waste form in accordance with ALARA practices, and grouts the Cs-free liquid to meet the applicable WAC

- $\quad U N E X$. The UNEX process concentrates the major isotopes, i.e., Cs, strontium ( $\mathrm{Sr}$ ), and the actinides by a liquid-liquid extraction process and disposes of a large volume of the waste as very low-level MLLW. The very small volume of separated, concentrated isotopes would probably require disposal in a deep geologic disposal facility

- $\quad$ Steam Reforming. This approach uses high temperature steam, and other additives to destroy the nitrates, reduce the overall volume of waste, and produce a dry granular product.

- Calcination. Use a process similar to the calcine process previously used at INTEC to reduce the volume of waste and produce a dry granular product.

- $\quad$ Acid Destruction. The process adds a reducing agent (formic acid) and uses high steam pressures and temperatures to make supersaturated "brine." The bottoms are then neutralized with $\mathrm{NaOH}$ to a $\mathrm{pH}$ of 8 to 10. When cooled, the brine solidifies, because the amount of dissolved solids in the brine exceeds the solubility limit for the remaining liquid. The evaporated slurry salt is then transferred to containers, where it solidifies upon cooling.

- $\quad$ Silica Gel. This proposed stabilization technology will absorb the NGLW on silica gel to stabilize it. This technology was rejected because it will not meet the WAC for a MLLW disposal site.

- Vitrification. The vitrification process involves converting the liquid waste and various glass forming additives to a vitrified solid form in a high temperature melter. The properties of the final product are very good.

- $\quad$ Direct Solification. Similar to CsIX/Grout, this option stabilizes the waste in grout for disposal at a MLLW site. This option does not remove the Cs and therefore results in a higher dose from the product.

- $\quad$ Evaporation and Solidification. The process uses high steam pressures and temperatures to make supersaturated "brine." When cooled, the brine solidifies, because the amount of dissolved solids in the brine exceeds the solubility limit for the remaining liquid. The evaporated slurry salt is then transferred to containers, where it solidifies upon cooling.

Block flow diagrams and other supporting data were developed and evaluated using the selection criteria developed by the evaluation team. The team used a process similar to the Kepner-Tregoe decision analysis method. This method establishes mandatory (Must) criteria and desirable (Want) criteria. The Want criteria are assigned weights based on their importance. The initial screening eliminates any option that does not meet the Must criteria. The remaining options are the compared using the Wants and each option is assigned a rating. Then, for each Want criterion, a score is calculated by taking the product of 
the weight and the rating. Finally, the optimum option is determined by summing the scores for the various Want criteria for the options.

The criteria addressed the following important parameters:

- The ability of the process to generate waste forms that meet the applicable waste acceptance criteria

- A measure of the technical maturity of the process under consideration

- A measure of the complexity of the process, which translates to cost and reliability of the process

- The volume of waste generated by the process and the estimated cost for disposing of that waste

- $\quad$ The risk that the process may meet strong regulatory or stakeholder resistance.

The evaluation team, consisting of representatives from Engineering, Cost Estimating, and Operations, assessed the broad range of technologies against these criteria. The results clearly indicated that a solidification technology, i.e., grouting the liquid waste, either as-received or with cesium ion exchange to reduce the dose from the final product, was the best choice. The other technologies were rated significantly below these two. Furthermore, sensitivity analyses of the impact of differences in the ratings confirmed that the solidification technologies were the optimum.

Of the two highest rated options, grouting as-received NGLW and CsIX/Grout, the CsIX/Grout process was selected as the basis for the facility design because the dose from the major waste volume was substantially reduced, thereby simplifying handling and minimizing the overall dose to the workers.

Additional details regarding the process selection are provided in Appendix D.

\subsubsection{Process Description}

The solidification process technology selected as the basis for the onsite facility feasibility study was solidification with cesium ion exchange (CsIX Grout). This process is slightly more complicated than the simple solidification process but will provide a low total dose to the worker. While either option (solidification or CsIX Grout) will be designed to meet the applicable dose limits to workers, the CsIX Grout process will provide a lower dose to the worker, in accordance with ALARA practices.

The CsIX Grout process consists of the following unit operations (see Appendix D for details):

- $\quad$ Preneutralization of the NGLW to approximately $1 \mathrm{M}$ acid

- $\quad$ Filtration to remove undissolved solids, and subsequent solids handling and packaging

- Cesium removal using ion exchange, and subsequent ion exchange resin handling and packaging

- $\quad$ Cs free liquid neutralization (to $\mathrm{pH} 2$ )

- $\quad$ Stabilization to meet the applicable WAC by grouting

- $\quad$ Loading and transport of waste products to the disposal site.

\subsubsection{Facility Description}

The NGLW treatment facility consists of two major sections, a shielded portion that is constructed of reinforced concrete that houses the undissolved solids filtration, preneutralization, and ion exchange operations, and a metal building system for the grouting, HVAC equipment, and administrative areas. Overall, this facility is about $120 \times 155 \mathrm{ft}$. A floor plan of the facility is provided in Figure 5 . 
Figure 5. Floor plan. 
The design of the shielded portion of the facility is roughly based on the pump-and-valve corridor concept, in which items with very infrequent maintenance requirements are placed in a shielded cell, while the more maintenance-intensive items (pumps, valves, and instrumentation) are located in a shielded corridor between the operating corridor (where personnel are located) and the shielded cells. In a typical pump-and-valve corridor design, expensive, remotely-operated equipment is used to maintain the components in the pump-and-valve $(\mathrm{P} \& \mathrm{~V})$ corridor. In this case, the radioactive contamination of the NGLW is less than that associated with the SBW and previous HLW operations so the equipment in the $\mathrm{P} \& \mathrm{~V}$ corridor will simply be flushed and decontaminated to levels that will allow hands-on maintenance. After the waste has passed through the solids filtration and ion exchange steps, the associated radiation dose is greatly reduced. The fluid passes to the "contact-handled" side of the operation.

Due to its size, the NGLW facility could not be located adjacent to CPP-604, which would be preferable for ease of access to the storage tanks. For the purposes of this study, it was located to the north of the tank farm. It could also be located east of NWCF. In either case, as noted previously, a new waste transfer line would be required to provide access to the storage tanks after the TFF was closed. The facility size is driven, in large part, by the ion exchange and undissolved solids handing operations. If this option is to be pursued, a trade-off study should be performed to compare the costs of a new transfer line against the options to minimize the footprint. For instance, the footprint could be substantially reduced by elimination of the solids handling and ion exchange operations but those changes would probably result in higher dose to the workers. Depending on the quantity and radiological characteristics of the undissolved solids, some solids handling may still be necessary. This emphasizes the point that characterization of the NGLW is needed early to determine system requirements. Reduction of duplicate tanks (with the attendant loss of operational flexibility) might also reduce the building size.

\subsubsection{Cost}

The total project cost for the onsite treatment facility is $\$ 85,980,157$, including contingency and escalation. A summary of the estimates in the major elements of the work breakdown structure is presented in Table 6. Given the phase of the project (feasibility), some of the cost accounts (e.g., Project Management, Engineering, Project Controls) are developed using percentages of the construction cost. These percentages are based on historical experience at the INEEL.

Table 6. Summary of costs for onsite facility.

\begin{tabular}{lrrrc}
\hline \multicolumn{1}{c}{ Description } & $\begin{array}{r}\text { Estimate } \\
\text { Subtotal }\end{array}$ & Escalation & Contingency & Total \\
\hline Project Management & $\$ 3,111,469$ & $\$ 393,562$ & $\$ 1,209,007$ & $\$ 4,714,038$ \\
Engineering & $\$ 6,559,955$ & $\$ 828,919$ & $\$ 2,147,212$ & $\$ 9,536,086$ \\
Technology Development & $\$ 4,950,000$ & $\$ 529,650$ & $\$ 1,929,754$ & $\$ 7,409,404$ \\
Project Controls & $\$ 2,159,567$ & $\$ 296,561$ & $\$ 791,992$ & $\$ 3,248,120$ \\
Project Administration & $\$ 746,708$ & $\$ 112,904$ & $\$ 183,183$ & $\$ 1,042,795$ \\
Procurement & $\$ 963,226$ & $\$ 130,806$ & $\$ 308,630$ & $\$ 1,402,662$ \\
ES\&H/QA & $\$ 1,474,400$ & $\$ 1,226,782$ & $\$ 4,461,166$ & $\$ 17,162,348$ \\
Construction & $\$ 24,290,441$ & $\$ 3,961,109$ & $\$ 9,970,451$ & $\$ 38,222,001$ \\
Startup and Testing & $\$ 2,065,019$ & $\$ 403,918$ & $\$ 773,767$ & $\$ 3,242,703$ \\
\hline Total Project Cost & $\$ 56,320,785$ & $\$ 7,884,211$ & $\$ 21,775,162$ & $\$ 85,980,157$ \\
\hline
\end{tabular}

Care should be taken when comparing these costs to the costs presented above for the commercial approaches, because the commercial proposals specifically excluded certain costs that must be covered by 
the project in one fashion or another. The engineering and construction cost presented here includes the costs for tie-in to the existing valve boxes and utility systems that the commercial proposals identified as part of the INEEL scope. Also, the onsite facility costs include the design, procurement, and construction of the solids-handling system, which was not identified as part of the subcontractor scope. Removing the solids-handling system costs (and the associated building costs) reduces the construction cost by $\$ 13.3 \mathrm{M}$ and reduces the overall project cost from $\$ 86.0 \mathrm{M}$ to $\$ 65.5 \mathrm{M}$.

The ES\&H/QA account will be needed in its entirety for either the commercial or the onsite facility approach. This account includes costs for permitting, safety analysis documentation, and quality assurance. Even though the subcontractor is supplying the equipment, DOE will require assurance that the operation will proceed safely and that all technical and safety limits have been established and that operations will remain within those limits or that mitigating procedures are identified. Both proposals stated that permitting would be the responsibility of the INEEL. The proposals for the commercial approach also identified a need for additional treatability studies when better data on the NGLW chemical, physical, and radiological properties are available. This is equivalent to the Technology Development account shown above. The Technology Development for the onsite facility would be higher than that for the commercial approach because additional unit operations (solids handling and ion exchange) are involved. Project management, project controls, and project administration activities will be needed for either the commercial approach or the onsite facility but should be less for the commercial approach.

\subsubsection{Life-Cycle Cost}

The life-cycle cost for this project was calculated using the procedures outlined in the Office of Management and Budget Circular A-94, Guidelines and Discount Rates for Benefit-Cost Analysis of Federal Programs and is included in Appendix E.

\subsubsection{Schedule}

A schedule for a project to design and construct this onsite facility is presented in Figure 6 . The design and construction of a new facility will have to meet the requirements of DOE Order 413.3, "Program and Project Management for the Acquisition of Capital Assets." As a result, the project critical path will be constrained by the DOE budget cycles as shown in Figure 6.

There are two budget cycles of concern to this project: the project engineering and design (PED) funding and the budget request for new construction. The PED funding provides for the preliminary and detailed design of the facility, while the budget request for new construction allocates funds for procurement and construction. Each of these cycles requires $1 \frac{1 / 2}{2}$ years from submittal of the request until authorization of the funds. This schedule assumes that the engineering and design request would be submitted during FY 2003, which would allow the preliminary design (formerly Title I design) activities to start at the beginning of FY 2005 (October 2004). The soonest the budget request for new construction could be submitted would be FY 2006, which would allow a construction start in FY 2008 (October 2007). The onsite facility could be constructed in time to provide the treatment capability needed by 2010, which is the time the storage tanks VES-WM-100, VES-WM-101, and VES-WM-102 will be filled to near capacity.

Delays in submitting either the PED request or the budget request for new construction would result in a schedule slip that impacts management of NGLW because the existing storage tanks would be filled to capacity. 


\section{CONCLUSIONS AND RECOMMENDATIONS}

\subsection{Waste Quantities and Composition}

Even though the chemical and radiological composition of the waste cannot be accurately specified at this time, certain conclusions can be drawn regarding the quantities and composition of the NGLW. Chemically, the concentrated NGLW will likely be higher in acid concentration than SBW because it results from decontamination solutions, which are often very concentrated nitric acid. Radiologically, it appears, based on very limited available data, that NGLW is less radioactively contaminated than SBW and is not expected to be TRU waste. Finally, the dissolved solids content of the NGLW is much less than that of SBW, which would affect application of certain treatment technologies such as evaporation, calcination, and steam reforming.

\subsection{Interfaces with Other INTEC Systems}

The proposed storage location for the NGLW, that is, in vessels VES-WM-100, VES-WM-101 and VES-WM-102, provides the capability to support the entire INTEC using existing waste transfer systems. The site selection for the NGLW treatment process, whether it is based on commercially supplied system or a dedicated onsite facility, should consider the changes to the INTEC configuration. For instance, the TFF will be closed as part of the overall ITFP and the closure of the valve boxes within the TFF could affect access to the NGLW treatment location. Also, closure of CPP-601 could affect the transfer of liquids from facilities such as FAST, FDP, and RAL. Finally, the NGLW management scheme should be re-assessed from time to time to address changes in liquid waste generation rates, should they occur.

ON-SITE NGLW TREATMENT FACILITY

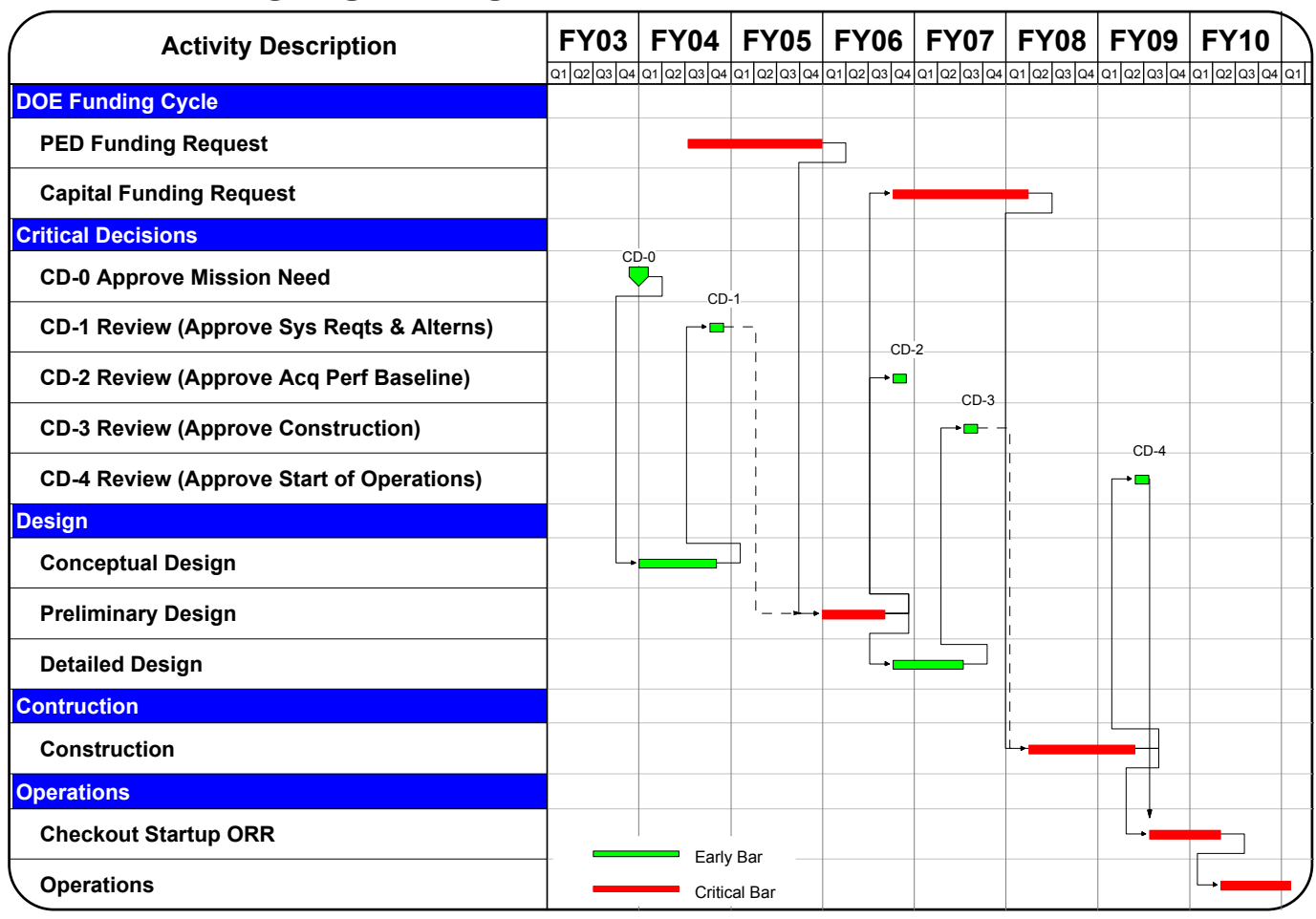

Figure 6. Project schedule. 


\subsection{Recommended NGLW Management Approach}

The recommended approach for management of NGLW is a combination of two of the options discussed above:

- $\quad$ Start segregating NGLW after September 2005 as mandated by DOE-ID and process the NGLW accumulated through 2010 with the SBW in the SBW treatment facility

- Employ subcontractors with commercial technologies to process the NGLW generated after the SBW treatment facility has completed its mission (assumed to be 2011).

The recommendation to start segregation of the NGLW is mainly driven by the potential that the SBW may eventually be determined to be HLW or that mixing the non-TRU NGLW with TRU SBW would not be considered good practice. If these issues can be resolved, there is no reason to implement the segregation of NGLW.

Given that the SBW treatment facility can be considered a sunk cost, the processing of the NGLW inventory through 2011 will incur only the additional operating and disposal costs. Estimates for the operating costs of the SBW treatment plant are not available because the treatment technology has yet to be decided. However, it seems reasonable to assume that the operating costs for treating the additional NGLW volume in the SBW plant would not be significantly different than the costs for treatment in any of the other options so the net additional cost is the difference in disposal costs as MLLW or TRU. This cost difference was estimated to be about $\$ 650,000$. These savings are predicated on the assumption that the NGLW can be mixed with the SBW, so that the treatment process is not affected by the differences between the SBW and NGLW.

The major risks associated with this approach are:

- The SBW treatment facility is not commissioned in time to support the processing needs of the NGLW

- $\quad$ There is a programmatic concern that mixing the non-TRU NGLW with the TRU SBW is perceived to be in violation of good waste management practices.

Either of the risks can be mitigated by scheduling a campaign with a subcontractor. That contractor must be provided adequate characterization data and sufficient lead-time to develop the specific process, procure and test equipment, and mobilize in the field.

Cost quoted in this report should be used as a basis of comparison between the options and not as a firm representation of the final cost of the systems and facilities. In particular, the differences in the implementation of the SBW treatment facility that are currently being evaluated will have a significant impact on the approach to be taken for management of NGLW.

\subsection{Costs}

There are large discrepancies between the costs quoted for the commercially supplied process and the on-site facility TPC. The majority of the differences can be attributed to two causes:

- $\quad$ The quotes from potential subcontractors do not include all the costs associated with the job as bid.

- The scope of the on-site facility was expanded to include capabilities not provided by the subcontractor-supplied systems. 
Items that were not included in the subcontractor estimates are itemized below:

Treatability Studies: treatability studies (analogous to the technology development noted in the onsite study) were identified as needed but no estimate was provided. Depending on the difficulty of obtaining samples and the amount of analytical work required, these costs could easily amount to $\$ 5 \mathrm{M}$.

RCRA Permitting: both commercial process studies identified obtaining permits as INEEL scope. The cost estimate for these activities is about $\$ 6.5 \mathrm{M}$ (including escalation and contingency).

Safety Analyses: Even though the work is performed by a subcontractor, the DOE safety rules will still apply. Preliminary and final safety analyses are estimated to add a total of $\$ 8.4 \mathrm{M}$.

Project Management: The project management costs associated with the subcontractor supplied system would probably be less than those for the on-site facility. Assuming the INEEL project management costs for the subcontractor supplied system are one-quarter that of the on-site facility, the additional cost would be about $\$ 1.2 \mathrm{M}$.

Operational Readiness Review (ORR): The subcontractor estimates did not include the INEEL costs associated with the ORR. The costs could be $\$ 0.75 \mathrm{M}$.

In total, these program costs add $\$ 21.9 \mathrm{M}$ to the overall project cost.

Features provided in the on-site design that are not included in the proposed designs from the commercial suppliers include a solids management system, ion exchange to remove cesium, the additional facility costs associated with housing these systems, and administrative space. In total, these additional features amount to an additional \$20M to \$25M.

The total cost for the treatment of the NGLW by a commercial subcontractor will certainly be higher than the estimates quoted. Programmatic costs that will be incurred regardless of the approach could add nearly $\$ 22 \mathrm{M}$ and additional equipment and construction costs may also be incurred. The cost of the on-site facility, on the other hand, provides a reasonable upper limit on the overall cost.

\subsection{Schedule}

A major consideration in selecting the commercially supplied option was the schedule flexibility provided by that option as compared to the on-site facility. As discussed previously, and shown in Figure 6 , the DOE budget cycle drives the schedule for a small capital project such as the on-site facility. At the earliest, if Approval of Mission Need were received at the beginning of FY 2004, the facility would be available for operations sometime in FY 2010.

\section{RISKS AND UNCERTAINTIES}

The following sections identify some of the risks and uncertainties that were identified as the study progressed.

\subsection{Technical Risks}

\subsubsection{Waste Quantities and Composition}

The uncertainties associated with the quantities of NGLW generated over time and its composition (both liquids and solids) are the most significant uncertainties associated with this report. The estimates 
used here were developed assuming minimal additional decontamination of existing facilities as they are closed. Furthermore, this study does not consider any new research or production missions for the INTEC.

As the study progressed, it became apparent that the quantity and composition of the undissolved solids in the waste could drastically affect the overall cost and complexity of the system. This impact is strongly affected by the fact that, for lack of better data, the NGLW undissolved solids were assumed to be the same chemical and radiological composition as the undissolved solids that have been obtained from samples of the SBW tanks. Clearly, the risks associated with the uncertainties in the volume or composition of the NGLW can be mitigated by timely characterization of the wastes before any treatment systems are designed. Other mitigation strategies for this risk depend, to a large extent, on the cause of the increase in volumes or the difference in composition. Obviously, if a new mission (or re-vitalization of the old reprocessing mission) were to develop, entire new waste management processes would be warranted. If the increase in liquid waste were due to a stricter requirement for "clean closure" of the INTEC facilities, implying greater use of decontamination fluids, the schedule for closure of facilities could be driven by the waste treatment capabilities. If other drivers for the closure schedule were identified, a new treatment facility (or adaptation of the SBW treatment facility) could resolve the problem.

The options considered here can generally accommodate moderate increases in the rate of production of NGLW after 2012. Since the tanks currently identified for storage of the NGLW (VES-WM-100, VES-WM-101, and VES-WM-102) will be nearly filled by 2010, moderate increases in NGLW production between 2005 and 2010 might require that the commercial supplier be brought in earlier.

\subsubsection{Coordination with Commercial Suppliers}

Any process, whether provided by commercial processes or designed for a dedicated onsite facility, will require some treatability studies to assure that the process will work as expected and to determine the final formulations for the various waste treatment recipes. Close coordination will be required to assure that all the requirements and waste characteristics are defined.

Facility and infrastructure modifications will also be needed from the INEEL, as well as application for and approval of the necessary environmental permits. These issues will have to be closely managed to assure that the commercial supplier is not surprised by additional requirements late in the project.

\subsection{Programmatic Risks}

\subsubsection{Waste Classification}

The first issue to be resolved regarding the NGLW is its classification. Some streams (e.g., FAST operations) are clearly not HLW. Other streams, particularly from HLW facilities, such as NWCF, should be assessed regarding their waste classifications. It is very likely these streams would be WIR by citation, but this should be confirmed before segregating the NGLW from SBW in 2005.

If the NGLW is not MLLW waste, as currently estimated, i.e., if it contains less that $100 \mathrm{nCi} / \mathrm{g}$ TRU contaminants, there may be a concern that mixing the NGLW with SBW is generating more TRU waste and is not in the spirit of best waste management practices. Given the current estimates, the NGLW is only a small percentage (7\%) of the total volume of liquid waste that will be processed for WIPP. The combined volume is well within the capacity of WIPP, and presents no special concerns with respect to chemical or radiological hazards. Nonetheless, if resistance to this approach were encountered, a 
mitigation strategy would be to use the commercial vendor to process the inventory of NGLW generated from 2005 through 201 las MLLW separately. The decision to adopt this strategy must be made with sufficient lead time so that the commercial supplier and the INEEL can perform the necessary tasks. The commercial supplier will have to finalize the treatment process and procure any equipment needed to support the special NGLW needs, while the INEEL would have to apply for and receive the necessary permits for treatment and provide the necessary infrastructure modifications. Then, the supplier can mobilize in the field before the storage capacity of the WM-100, WM-101, and WM-102 tanks would be exceeded.

\subsubsection{Tank Waste Classification and Permitting}

The tanks proposed for storage of the NGLW, VES-WM-100, -WM-101, and -WM-102, may need a WIR determination conducted to reclassify them as other than HLW and must be permitted for use as RCRA hazardous waste storage tanks. These tanks were formerly used in operations involving HLW (storing first, second, and third cycle raffinates) and are currently considered HLW. An evaluation WIR may be needed to allow them to be managed as other than HLW. The concentrated NGLW is hazardous waste according to RCRA and these tanks must be permitted for use as hazardous waste storage tanks. They are currently included in the permit application for the INTEC ETS and no problems are anticipated with this permit application. However, if either of these activities should fail, the tanks could not be used for storage of NGLW and segregation of NGLW could not commence in 2005.

\subsection{Cost Risks}

This project is in the very early stages, and many of the technical and programmatic uncertainties can affect the overall cost.

\subsection{Schedule Risks}

\subsubsection{SBW Treatment Facility Delay}

If the commissioning of the SBW treatment facility were to be delayed (for any number of reasons), the capacity of the NGLW storage tanks could be reached. One mitigation strategy for this risk is that the commercial supplier can be employed if sufficient lead time is provided. As noted in the discussion regarding the dedicated onsite facility, the DOE funding cycle sets the critical path for the capital project. It would be difficult to respond with a dedicated facility design if the start is significantly delayed unless appropriation of funding was handled on a special-case basis.

\section{REFERENCES}

1. Barnes, C. M., to Landman, W. H., "NGLW Volumes and Compositions for Treatment Study," Rev. 1, CMB-07-02, April 8, 2002.

2. Duratek Inc., INEEL Newly Generated Liquid Waste (NGLW) Feasibility Study Report, ER-G-02-01, Rev. 0, June 2002.

3. Science Applications International Corporation, Feasibility Study for Treatment of the Newly Generated Waste (NGLW) at the Idaho Nuclear Technology and Engineering Center (INTEC), Draft, July 2002.

4. Most, W. to Perry, K. J., electronic communication, "Cost Approximation for INEEL SBW," June 11, 2002. 


\section{Appendix A NGLW Composition Estimates}





\section{Appendix B}

\section{NGLW Generation and Disposal Cost Analysis}





\section{Appendix C}

Hold for SBW Processing Study 



\section{Appendix D}

Commercial Process Feasibility Studies 

Appendix E

On-site NGLW Treatment Facility Study 